\title{
REVISED What is open peer review? A systematic review [version
}

\section{2; peer review: 4 approved]}

\author{
Tony Ross-Hellauer (iD)
}

Göttingen State and University Library, University of Göttingen, Göttingen, 37073, Germany

V2 First published: 27 Apr 2017, 6:588

https://doi.org/10.12688/f1000research.11369.1

Latest published: 31 Aug 2017, 6:588

https://doi.org/10.12688/f1000research.11369.2

\section{Abstract}

Background: "Open peer review” (OPR), despite being a major pillar of Open Science, has neither a standardized definition nor an agreed schema of its features and implementations. The literature reflects this, with numerous overlapping and contradictory definitions. While for some the term refers to peer review where the identities of both author and reviewer are disclosed to each other, for others it signifies systems where reviewer reports are published alongside articles. For others it signifies both of these conditions, and for yet others it describes systems where not only "invited experts" are able to comment. For still others, it includes a variety of combinations of these and other novel methods.

Methods: Recognising the absence of a consensus view on what open peer review is, this article undertakes a systematic review of definitions of "open peer review" or "open review", to create a corpus of 122 definitions. These definitions are systematically analysed to build a coherent typology of the various innovations in peer review signified by the term, and hence provide the precise technical definition currently lacking.

Results: This quantifiable data yields rich information on the range and extent of differing definitions over time and by broad subject area. Quantifying definitions in this way allows us to accurately portray exactly how ambiguously the phrase "open peer review" has been used thus far, for the literature offers 22 distinct configurations of seven traits, effectively meaning that there are 22 different definitions of OPR in the literature reviewed.

Conclusions: I propose a pragmatic definition of open peer review as an umbrella term for a number of overlapping ways that peer review models can be adapted in line with the aims of Open Science, including making reviewer and author identities open, publishing review reports and enabling greater participation in the peer review process.

\section{Keywords}

open peer review, Open Science, scholarly communication, research evaluation, publishing

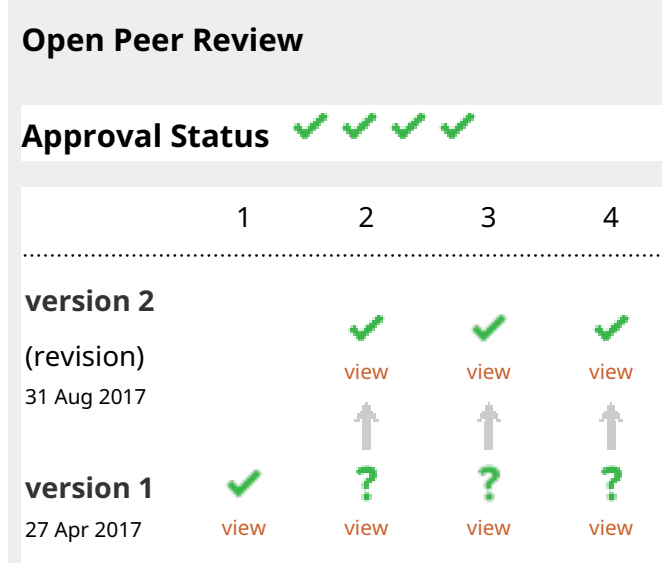

1. Richard Walker (D), Swiss Federal Institute of Technology in Lausanne, Geneva,

Switzerland

2. Theodora Bloom [D, The BMJ, London, UK

3. Bahar Mehmani (D), RELX Group,

Amsterdam, The Netherlands

4. Emily Ford ID, Portland State University, Portland, USA

Any reports and responses or comments on the article can be found at the end of the article. 
This article is included in the Research on

Research, Policy \& Culture gateway.

Corresponding author: Tony Ross-Hellauer (ajcross01@gmail.com)

Author roles: Ross-Hellauer T: Conceptualization, Data Curation, Formal Analysis, Investigation, Methodology, Project Administration, Resources, Software, Supervision, Validation, Visualization, Writing - Original Draft Preparation, Writing - Review \& Editing

Competing interests: This work was conducted as part of the OpenAIRE2020 project, an EC-funded initiative to implement and monitor Open Access and Open Science policies in Europe and beyond.

Grant information: This work is funded by the European Commission H2020 project OpenAIRE2020 (Grant agreement: 643410, Call: H2020-EINFRA-2014-1)

The funders had no role in study design, data collection and analysis, decision to publish, or preparation of the manuscript.

Copyright: ( 2017 Ross-Hellauer T. This is an open access article distributed under the terms of the Creative Commons Attribution License, which permits unrestricted use, distribution, and reproduction in any medium, provided the original work is properly cited.

How to cite this article: Ross-Hellauer T. What is open peer review? A systematic review [version 2; peer review: 4 approved]

F1000Research 2017, 6:588 https://doi.org/10.12688/f1000research.11369.2

First published: 27 Apr 2017, 6:588 https://doi.org/10.12688/f1000research.11369.1 


\section{REVISED Amendments from Version 1}

The description of traditional peer review in the Background section has been revised to clarify the role of peer review in scholarly communication

The methodology section has been expanded to more completely describe the search strategy and inclusion criteria for the study.

A new section and figure have been added to the results section to examine disciplinary differences amongst definitions.

One figure was previously incorrect, as it included an extra row. The figure (Figure 6 in version 1; Figure 7 in version 2) has now been corrected

Two new sections have been added to the discussion which make clearer (1) the particular problems with traditional peer review that each OPR trait aims to address, and (2) how each trait can be related to the broader agenda of Open Science (a new figure is also added)

The conclusion has been expanded to further clarify the article's findings and limitations.

A Conflict of Interest statement has been added to more explicitly acknowledge the author's relationship to OpenAIRE.

See referee reports

\section{Introduction}

"Open review and open peer review are new terms for evolving phenomena. They don't have precise or technical definitions. No matter how they're defined, there's a large area of overlap between them. If there's ever a difference, some kinds of open review accept evaluative comments from any readers, even anonymous readers, while other kinds try to limit evaluative comments to those from "peers" with expertise or credentials in the relevant field. But neither kind of review has a special name, and I think each could fairly be called "open review" or "open peer review"." - Peter Suber, email correspondence, $2007^{1}$.

As with other areas of "open science" (Pontika et al., 2015), "open peer review" (OPR) is a hot topic, with a rapidly growing literature that discusses it. Yet, as has been consistently noted (Ford, 2013; Hames, 2014; Ware, 2011), OPR has neither a standardized definition, nor an agreed schema of its features and implementations. The literature reflects this, with a myriad of overlapping and often contradictory definitions. While the term is used by some to refer to peer review where the identities of both author and reviewer are disclosed to each other, for others it signifies systems where reviewer reports are published alongside articles. For others it signifies both of these conditions, and for yet others it describes systems where not only "invited experts" are able to comment. For still others, it includes a variety of combinations of these and other novel methods. The previous major attempt to resolve these elements

\footnotetext{
${ }^{1}$ This quote was found on the P2P Foundation Wiki (http://wiki.p2pfoundation.net/Open_Peer_Review, accessed $18^{\text {th }}$ July 2016). Its provenance is uncertain, even to Suber himself, who recently advised in personal correspondence (19 ${ }^{\text {th }}$ August 2016): "I might have said it in an email (as noted). But I can't confirm that, since all my emails from before 2009 are on an old computer in a different city. It sounds like something I could have said in 2007. If you want to use it and attribute it to me, please feel free to note my own uncertainty!"
}

systematically to provide a unified definition (Ford, 2013), discussed later, unfortunately ultimately confounds rather than resolves these issues.

In short, things have not improved much since Suber made his astute observation. This continuing imprecision grows more problematic over time, however. As Mark Ware notes, "it is not always clear in debates over the merits of OPR exactly what is being referred to" (Ware, 2011). Differing flavours of OPR include independent factors (open identities, open reports, open participation, etc.), which have no necessary connection to each other, and very different benefits and drawbacks. Evaluation of the efficacy of these differing variables and hence comparison between differing systems is therefore problematic. Discussions are potentially sidetracked when claims are made for the efficacy of "OPR" in general, despite critique usually being focussed on one element or distinct configuration of OPR. It could even be argued that this inability to define terms is to blame for the fact that, as Nicholas Kriegskorte has pointed out, "we have yet to develop a coherent shared vision for "open evaluation" (OE), and an OE movement comparable to the OA movement" (Kriegeskorte, 2012).

To resolve this, I undertake a systematic review of the definitions of "open peer review" or "open review", to create a corpus of more than 120 definitions. These definitions have been systematically analysed to build a coherent typology of the many different innovations in peer review signified by the term, and hence provide the precise technical definition that is currently lacking. This quantifiable data yields rich information on the range and extent of differing definitions over time and by broad subject area. Based on this work, I propose a pragmatic definition of OPR as an umbrella term for a number of overlapping ways that peer review models can be adapted in line with the aims of Open Science, including making reviewer and author identities open, publishing review reports and enabling greater participation in the peer review process.

\section{Background}

\section{Problems with peer review}

Peer review is the formal quality assurance mechanism whereby scholarly manuscripts (e.g. journal articles, books, grant applications and conference papers) are made subject to the scrutiny of others, whose feedback and judgements are then used to improve works and make final decisions regarding selection (for publication, grant allocation or speaking time). Peer review usually performs two distinct functions: (1) technical evaluation of the validity or soundness of a work in its methodology, analysis and argumentation (answering the question "is it good scholarship?"), and (2) assisting editorial selection by assessing the novelty or expected impact of a work ("is it exciting, innovative or important scholarship?", "is it right for this journal, conference or funding call?"). The two processes need not be entwined, and some journals such as PLOS ONE and PeerJ, have begun to adopt models where reviewers are asked to focus only on technical soundness.

This broad system is perhaps more recent than one might expect, with its main formal elements only in general use since the mid-twentieth century in scientific publishing (Spier, 2002). 
Researchers agree that peer review per se is necessary, but most find the current model sub-optimal. Ware's 2008 survey, for example, found that an overwhelming majority $(85 \%)$ agreed that "peer review greatly helps scientific communication" and that even more (around 90\%) said their own last published paper had been improved by peer review. Yet almost two thirds $(64 \%)$ declared that they were satisfied with the current system of peer review, and less than a third (32\%) believed that this system was the best possible (Ware, 2008). A recent follow-up study by the same author reported a slight increase in the desire for improvements in peer review (Ware, 2016)

Widespread beliefs that the current model is sub-optimal can be attributed to the various ways in which traditional peer review has been subject to criticism. These criticisms apply to differing levels, with some concerning the work of peer reviewers themselves, and others more concerned with editorial decisions based upon or affecting peer review. I next give a brief overview of these various criticisms of traditional peer review:

- Unreliability and inconsistency: Reliant upon the vagaries of human judgement, the objectivity, reliability, and consistency of peer review are subject to question. Studies show reviewers' views tend to show very weak levels of agreement (Kravitz et al., 2010; Mahoney, 1977), at levels only slightly better than chance (Herron, 2012; Smith, 2006). Studies suggest decisions on rejection or acceptance are similarly inconsistent. For example, Peters and Ceci's classic study found that eight out of twelve papers were rejected for methodological flaws when resubmitted to the same journals in which they had already been published (Peters \& Ceci, 1982). This inconsistency is mirrored in peer review's inability to prevent errors and fraud from entering the scientific literature. Reviewers often fail to detect major methodological failings (Schroter et al., 2004), with eminent journals (whose higher rejection rates might suggest more stringent peer review processes) seeming to perform no better than others (Fang et al., 2012). Indeed, Fang and Casadevall found that the frequency of retraction is strongly correlated with the journal impact factor (Fang \& Casadevall, 2011). Whatever the cause, recent sharp rises in the number of retracted scientific publications (Steen et al., 2013) testify that peer review sometimes fails in its role as the gatekeeper of science, allowing errors and fraudulent material to enter the literature. At an editorial level, peer review's other role, of guiding decisions that should in theory filter the best work into the best journals, also seems to be found wanting. Many articles in top journals remain poorly cited, while many of the most highly-cited articles in their fields are published in lower-tier journals (Jubb, 2016).

- Delay and expense: The period from submission to publication at many journals can often exceed one year, with much of this time taken up by peer review. This delay slows down the availability of results for further research and professional exploitation. The work undertaken in this period is also expensive, with the global costs of reviewers' time estimated at $£ 1.9$ bn in 2008 (Research Information Network [RIN], 2008), a figure which does not take into account the coordinating costs of publishers, or the time authors spend revising and resubmitting manuscripts (Jubb, 2016). These costs are greatly exacerbated by the current system in which peer review is managed by each journal, such that the same manuscript may be peer reviewed many times over as it is successively rejected and resubmitted until it finds acceptance. It could be argued that these issues relate more to editorial process than peer review per se. However, as we shall see, various new publishing models which encompass innovations in peer review (including open peer review), have the potential to address such issues.

- Lack of accountability and risks of subversion: The "black-box" nature of traditional peer review gives reviewers, editors and even authors a lot of power to potentially subvert the process. At the editorial level, lack of transparency means that editors can unilaterally reject submissions or shape review outcomes by selecting reviewers based on their known preference for or aversion to certain theories and methods (Travis \& Collins, 1991). Reviewers, shielded by anonymity, may act unethically in their own interests by concealing conflicts of interest. Smith, an experienced editor, for example, reports reviewers stealing ideas and passing them off as their own, or intentional blocking or delaying publication of competitors' ideas through harsh reviews (Smith, 2006). Equally, they may simply favour their friends and target their enemies. Authors, meanwhile, can manipulate the system by writing reviews of their own work via fake or stolen identities (Kaplan, 2015).

- Social and publication biases: Although often idealized as impartial, objective assessors, in reality studies suggest that peer reviewers may be subject to social biases on the grounds of gender (Budden et al., 2008; Lloyd, 1990; Tregenza, 2002), nationality (Daniel, 1993; Ernst \& Kienbacher, 1991; Link, 1998), institutional affiliation (Dall'Aglio, 2006; Gillespie et al., 1985; Peters \& Ceci, 1982), language (Cronin, 2009; Ross et al., 2006; Tregenza, 2002) and discipline (Travis \& Collins, 1991). Other studies suggest so-called "publication bias", where prejudices against specific categories of works shape what is published. Publication bias can take many forms. First is a preference for complexity over simplicity in methodology (even if inappropriate, c.f. Travis \& Collins, 1991) and language (Armstrong, 1997). Next, "confirmatory bias" is theorized to lead to conservatism, biasing reviewers against innovative methods or results contrary to dominant theoretical perspectives (Chubin \& Hackett, 1990; Garcia et al., 2016; Mahoney, 1977). Finally, factors like the pursuit of "impact" and "excellence" (Moore et al., 2017) mean that editors and reviewers seem primed to prefer positive results over negative or neutral ones (Bardy, 1998; Dickersin et al., 1992; Fanelli, 2010; Ioannidis, 1998), and to disfavour replication studies (Campanario, 1998; Kerr et al., 1977).

- Lack of incentives: Traditional peer review provides little in the way of incentives for reviewers, whose work is almost exclusively unpaid and whose anonymous contributions cannot be recognised and hence rewarded (Armstrong, 1997; Ware, 2008).

- Wastefulness: Reviewer comments often add context or point to areas for future work. Reviewer disagreements can expose 
areas of tension in a theory or argument. The behind-the-scenes discussions of reviewers and authors can also guide younger researchers in learning review processes. Readers may find such information helpful and yet at present, this potentially valuable additional information is wasted.

In response to these criticisms, a wide variety of changes to peer review have been suggested (see the extensive overviews in Tennant et al., 2017; Walker \& Rocha da Silva, 2015). Amongst these innovations, many have been labelled as "open peer review" at one time or another. As we shall see, these innovations labelled as OPR in fact encompass a wide variety of discrete ways in which peer review can be "opened up". Each of these distinct traits are theorized to address one or more of the shortcomings listed above, but no trait is claimed to address all of them and sometimes their aims may be in conflict. These points will be addressed fully in the discussion section.

\section{The contested meaning of open peer review}

The diversity of the definitions provided for open peer review can be seen by examining just two examples. The first one is, to my knowledge, the first recorded use of the phrase "open peer review":

"[A]n open reviewing system would be preferable. It would be more equitable and more efficient. Knowing that they would have to defend their views before their peers should provide referees with the motivation to do a good job. Also, as a side benefit, referees would be recognized for the work they had done (at least for those papers that were published). Open peer review would also improve communication. Referees and authors could discuss difficult issues to find ways to improve a paper, rather than dismissing it. Frequently, the review itself provides useful information. Should not these contributions be shared? Interested readers should have access to the reviews of the published papers." (Armstrong, 1982)

"[O]pen review makes submissions OA [open access], before or after some prepublication review, and invites community comments. Some open-review journals will use those comments to decide whether to accept the article for formal publication, and others will already have accepted the article and use the community comments to complement or carry forward the quality evaluation started by the journal." (Suber, 2012)

Within just these two examples, there are already a multitude of factors at play, including the removal of anonymity, the publishing of review reports, interaction between participants, crowdsourcing of reviews, and making manuscripts public pre-review, amongst others. But each of these are distinct factors, presenting separate strategies for openness and targeting differing problems. For example, disclosure of identities aims usually at increasing accountability and minimizing bias, c.f. "referees should be more highly motivated to do a competent and fair review if they may have to defend their views to the authors and if they will be identified with the published papers" (Armstrong, 1982). Publication of reports, on the other hand, also tackles problems of incentive (reviewers can get credit for their work) and wastefulness (reports can be consulted by readers). Moreover, these factors need not necessarily be linked, which is to say that they can be employed separately: identities can be disclosed without reports being published, and reports published with reviewer names withheld, for example.

This diversity has led many authors to acknowledge the essential ambiguity of the term "open peer review" (Hames, 2014; Sandewall, 2012; Ware, 2011). The major attempt thus far to bring coherence to this confusing landscape of competing and overlapping definitions, is Emily Ford's paper "Defining and Characterizing Open Peer Review: A Review of the Literature" (Ford, 2013). Ford examined thirty-five articles to produce a schema of eight "common characteristics" of OPR: signed review, disclosed review, editor-mediated review, transparent review, crowdsourced review, prepublication review, synchronous review, and postpublication review. Unfortunately, however, Ford's paper fails to offer a definitive definition of OPR, since despite distinguishing eight "common characteristics" of OPR, Ford nevertheless tries to reduce it to merely one: open identities: "Despite the differing definitions and implementations of open peer review discussed in the literature, its general treatment suggests that the process incorporates disclosure of authors' and reviewers' identities at some point during an article's review and publication" (p. 314). Summing up her argument elsewhere, she says: "my previous definition ... broadly understands OPR as any scholarly review mechanism providing disclosure of author and referee identities to one another" (Ford, 2015). But the other elements of her schema do not reduce to this one factor. Many definitions do not include open identities at all. This hence means that although Ford claims to have identified several features of OPR, she in fact is asserting that there is only one defining factor (open identity), which leaves us where we started. Ford's schema is also problematic elsewhere: it lists "editor-mediated review" and "pre-publication review" as distinguishing characteristics, despite these being common traits of traditional peer review; it includes questionable elements such as the purely "theoretical" "synchronous review"; and some of its characteristics do not seem to be "base elements", but complexes of other traits - for example, the definition of "transparent review" incorporates other characteristics such as open identities (which Ford terms "signed review") and open reports ("disclosed review").

\section{Method: A systematic review of previous definitions}

To resolve this ambiguity, I performed a review of the literature for articles discussing "open review" or "open peer review", extracting a corpus of 122 definitions of OPR. I first searched Web of Science (WoS) for "TOPIC: ("open review" OR "open peer review")", with no limitation on date of publication, yielding a total of 137 results (searched on 12th July 2016). These records were then each individually examined for relevance and a total of 57 were excluded. 21 results (all BioMed Central publications) had been through an OPR process (which was mentioned in the abstract) but did not themselves touch on the subject of OPR; 12 results used the phrase "open review" to refer to a literature review with a flexible methodology; 12 results were for the review of objects classed "out of scope" (i.e. academic articles, books, conference submissions, data - examples included guidelines for clinical or therapeutic techniques, standardized terminologies, patent applications, and court judgements); 7 results were not in the English language; and 5 results were duplicate entries in WoS. This left a total of 80 relevant articles which mentioned either "open peer review" or "open review". 
The same search terms were applied to find sources in other academic databases (Google Scholar, PubMed, ScienceDirect, JSTOR and Project Muse). In addition, the first 10 pages of search results for these terms in Google and Google Books (search conducted $18^{\text {th }}$ July 2016) were examined to find references in "grey literature" (blogs, reports, white papers) and books respectively. Finally, the author examined the reference sections of identified publications, especially bibliographies and literature reviews, to find further references. Duplicate results were discarded and the above exclusion criteria applied to add a further 42 definitions to the corpus. The dataset is available online (Ross-Hellauer, 2017, http://doi.org/10.5281/zenodo.438024).

Each source was then individually examined for its definition of OPR. Where no explicit definition (e.g. "OPR is ...") was given, implicit definitions were gathered from contextual statements. For instance, "reviewers can notify the editors if they want to opt-out of the open review system and stay anonymous" (Janowicz \& Hitzler, 2012) is taken to endorse a definition of OPR as incorporating open identities. In a few cases, sources defined OPR in relation to the systems of specific publishers (e.g., F1000Research, BioMed Central and Nature), and so were taken to implicitly endorse those systems as definitive of OPR.

In searching only for the terms "open review" and "open peer review", the study explicitly limits itself only to that literature which uses these terms. It is hence important to note that it is likely that other studies have described or proposed innovations to peer review which have aims similar to those identified by this study.
However, if they have not explicitly used the label "open review" or "open peer review" in conjunction with these systems, those studies would necessarily fall outside of scope. For example, "post-publication peer review" (PPPR) is clearly a concept closelyrelated to OPR, but unless sources explicitly equate the two, sources discussing PPPR are not included in this review. It is acknowledged that this focus on the distinct usages of the term OPR, rather than on all sources which touch on the various aims and ideas which underlie such systems, limits the scope of this study.

\section{Results}

The number of definitions of OPR over time show a clear upward trend, with the most definitions in a single year coming in 2015. The distribution shows that except for some outlying definitions in the early 1980s, the phrase "open peer review" did not really enter academic discussion until the early 1990s. At that time, the phrase seems to have been used largely to refer to non-blinded review (i.e. open identities). There is then a big upswing from the early-mid 2000s onwards, which perhaps correlates with the rise of the rise of the openness agenda (especially open access, but also open data and open science more generally) over that period (Figure 1). Most of the definitions, $77.9 \%$ ( $n=95)$, come from peer-reviewed journal articles, with the second largest sources being books and blog posts. Other sources include letters to journals, news items, community reports and glossaries (Figure 2). As shown in Figure 3, the majority of definitions $(51.6 \%)$ were identified to be primarily concerned with peer-review of Science, Technology, Engineering and Medicine (STEM) subject material, while 10.7\% targeted material from Social Sciences and Humanities (SSH) material. The

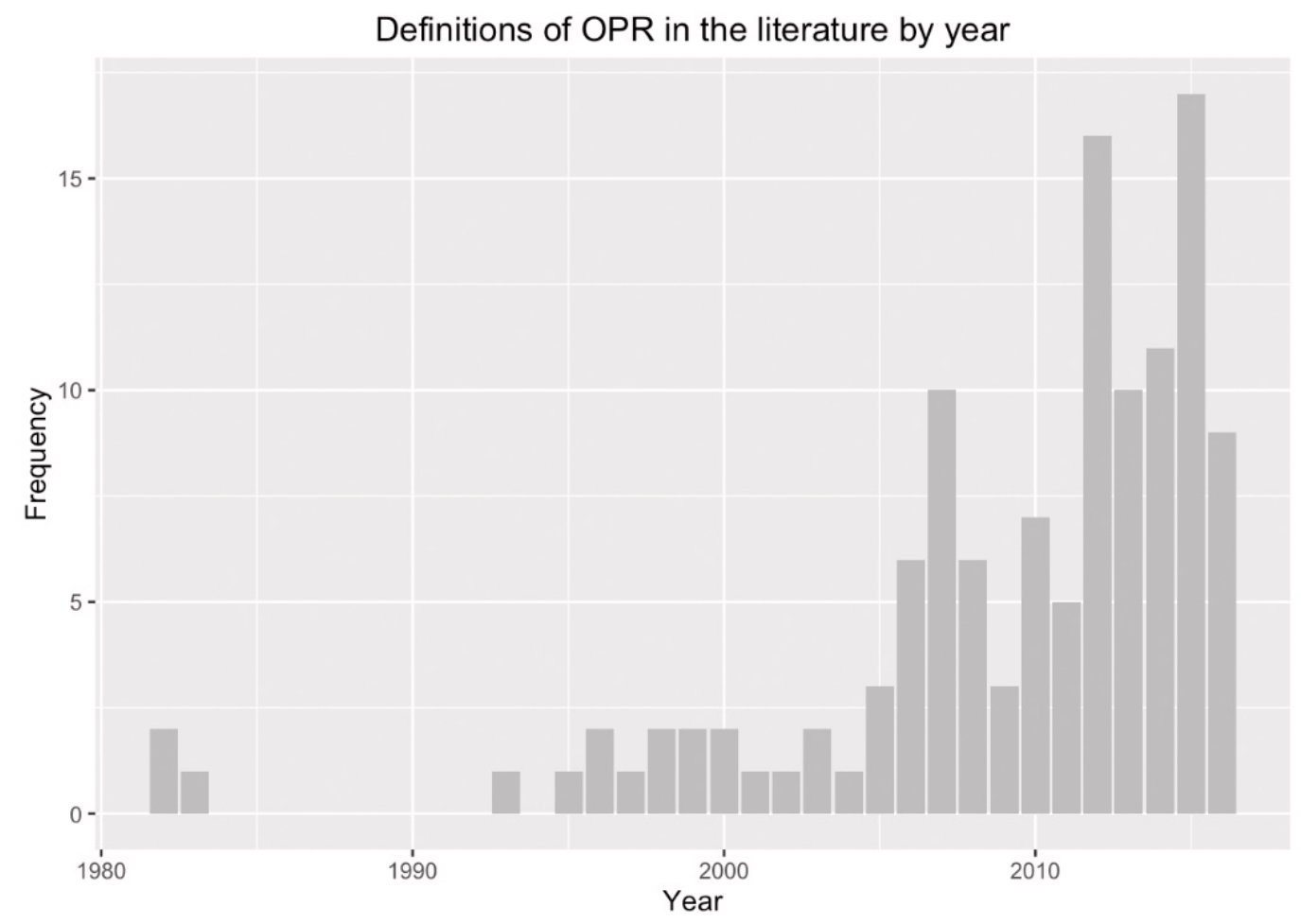

Figure 1. Definitions of OPR in the literature by year. 


\section{Source-type of definition}

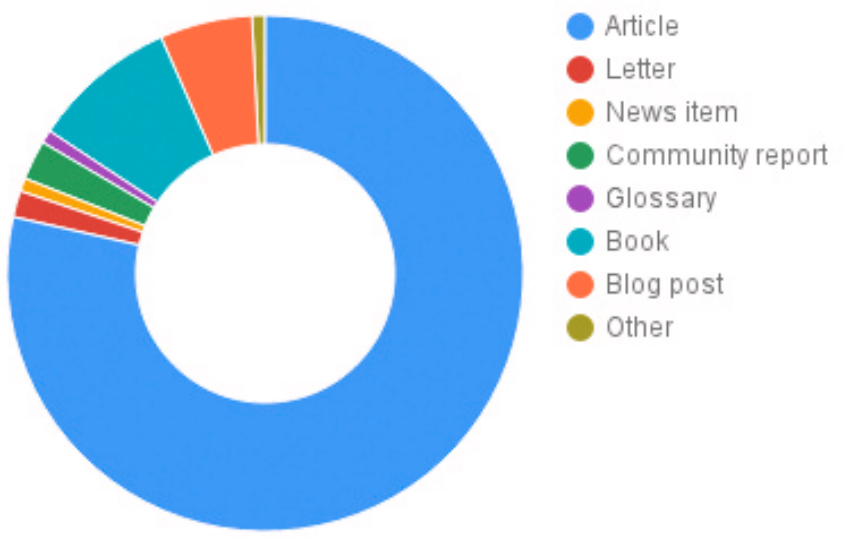

Figure 2. Breakdown of OPR definitions by source.

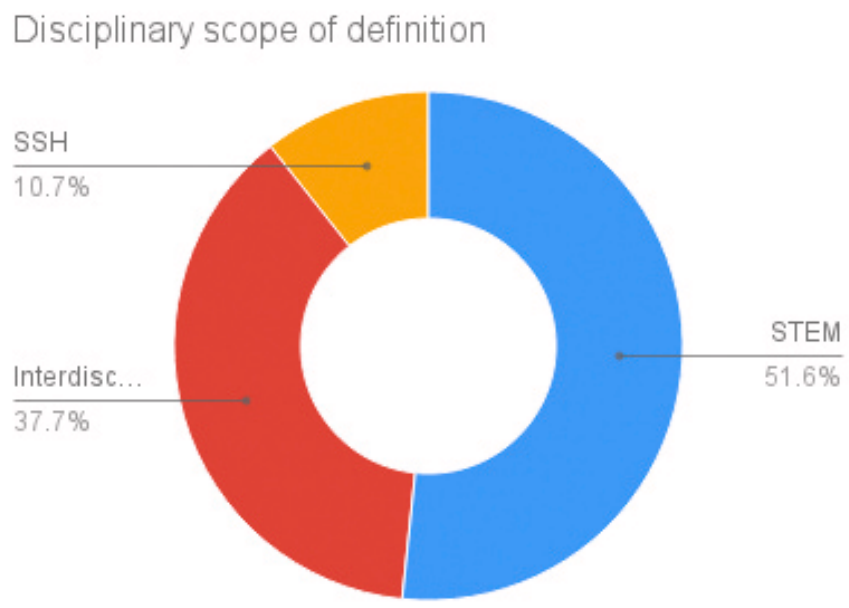

Figure 3. Breakdown of OPR definitions by disciplinary scope.

remainder $(37.7 \%)$ were interdisciplinary. Meanwhile, regarding the target of the OPR mentioned in these articles (Figure 4), most were referring to peer review of journal articles (80.7\%), with $16 \%$ not specifying a target (16\%), and a small number of articles also referring to review of data, conference papers and grant proposals.

Sixty-eight percent $(n=83)$ of the 122 definitions identified were explicitly stated, $37.7 \%(n=46)$ implicitly stated, and $5.7 \%(n=7)$ contained both explicit and implicit information.

The extracted definitions were examined and classified against an iteratively constructed taxonomy of OPR traits. Nickerson et al. (2013) advise that the development of a taxonomy should begin by identifying the appropriate meta-characteristic - in this case distinct individual innovations to the traditional peer review system. An iterative approach then followed, in which dimensions given in the literature were applied to the corpus of definitions and gaps/overlaps in the OPR taxonomy identified. Based on this, new traits or distinctions were introduced so that in the end, a schema of seven OPR traits was produced:

\section{What is being reviewed?}

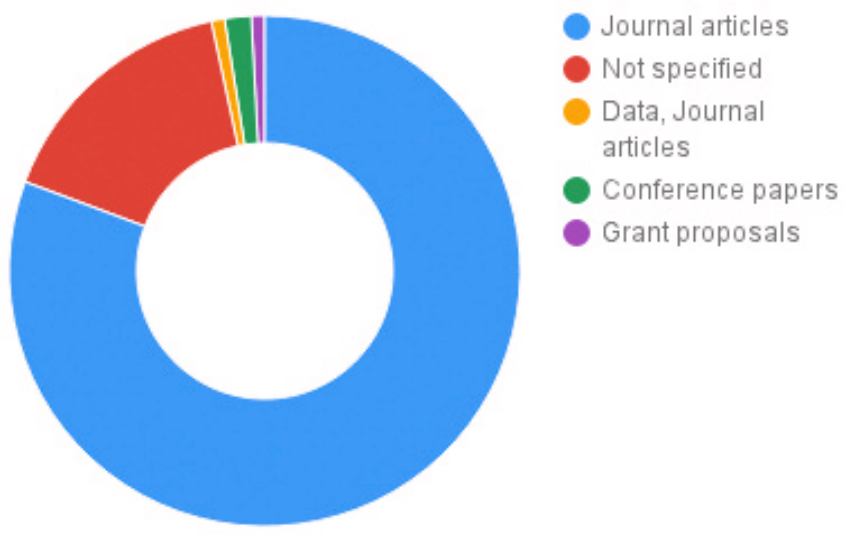

Figure 4. Breakdown of OPR definitions by type of material being reviewed.

- Open identities: Authors and reviewers are aware of each other's identity

- Open reports: Review reports are published alongside the relevant article.

- Open participation: The wider community are able to contribute to the review process.

- Open interaction: Direct reciprocal discussion between author(s) and reviewers, and/or between reviewers, is allowed and encouraged.

- Open pre-review manuscripts: Manuscripts are made immediately available (e.g., via pre-print servers like arXiv) in advance of any formal peer review procedures.

- Open final-version commenting: Review or commenting on final "version of record" publications.

- Open platforms (“decoupled review"): Review is facilitated by a different organizational entity than the venue of publication.

The core traits are easily identified, with just three covering more than $99 \%$ of all definitions: Open identities combined with open reports cover $116(95.1 \%)$ of all records. Adding open participations leads to a coverage of $121(99.2 \%)$ records overall. As seen in Figure 5, open identities is by far the most prevalent trait, present in $90.1 \%(n=110)$ of definitions. Open reports is also present in the majority of definitions $(59.0 \%, \mathrm{n}=72)$, while open participation is part of around a third. Open pre-review manuscripts $(23.8 \%$, $\mathrm{n}=29)$ and open interaction $(20.5 \%, \mathrm{n}=25)$ are also a fairly prevalent part of definitions. The outliers are open final version commenting $(4.9 \%)$ and open platforms $(1.6 \%)$.

If we break down these traits by the disciplinary-focus of the definition source, we observe some interesting differences between STEM- and SSH-focused sources (Figure 6). Of those sources whose definitions were identified to be primarily concerned with peer-review of SSH-subject material, we observe that in comparison to STEM, there is less emphasis on open identities (present 


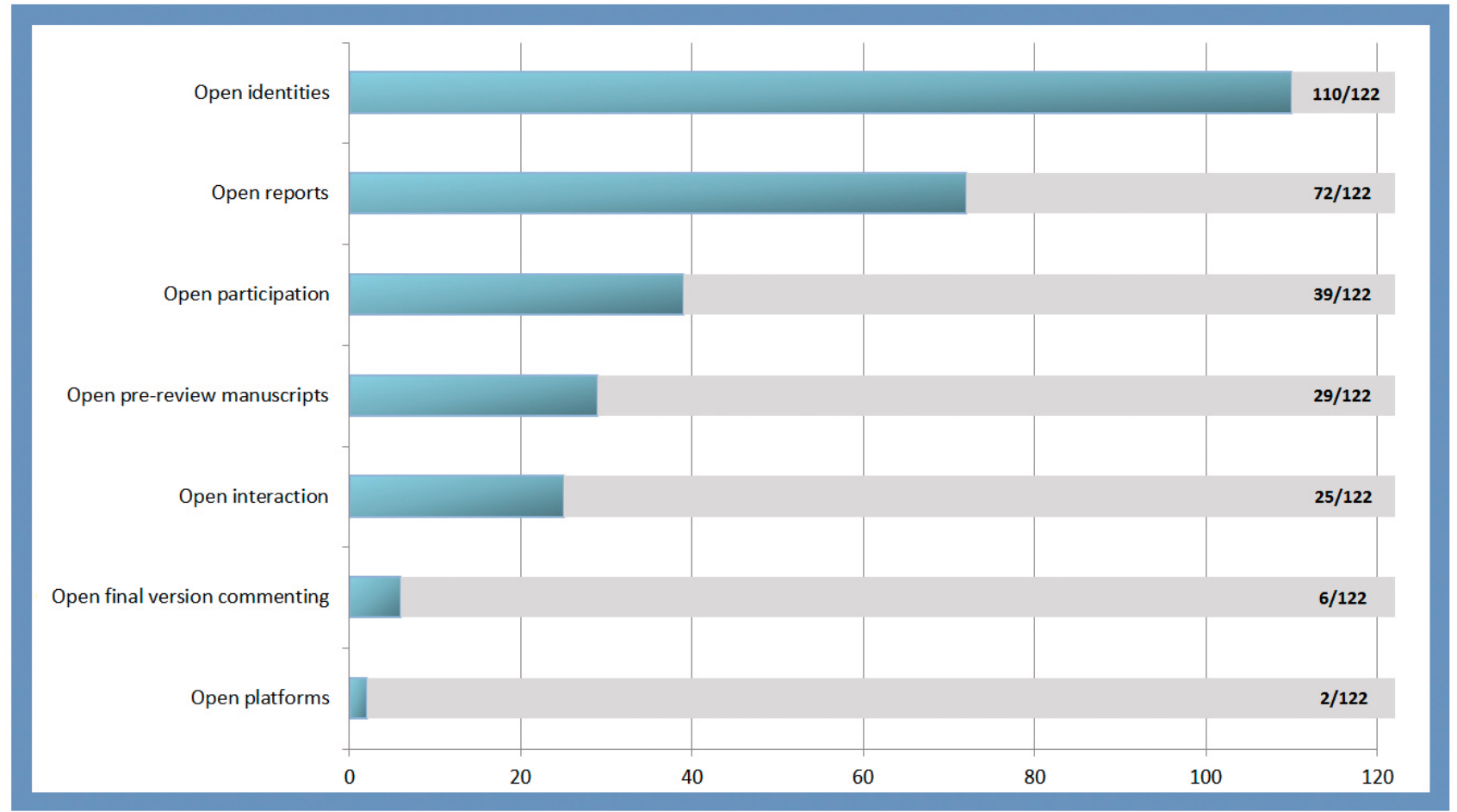

Figure 5. Distribution of OPR traits amongst definitions.

Prevalence of traits (as percentage) within definitions by disciplinary focus of definition

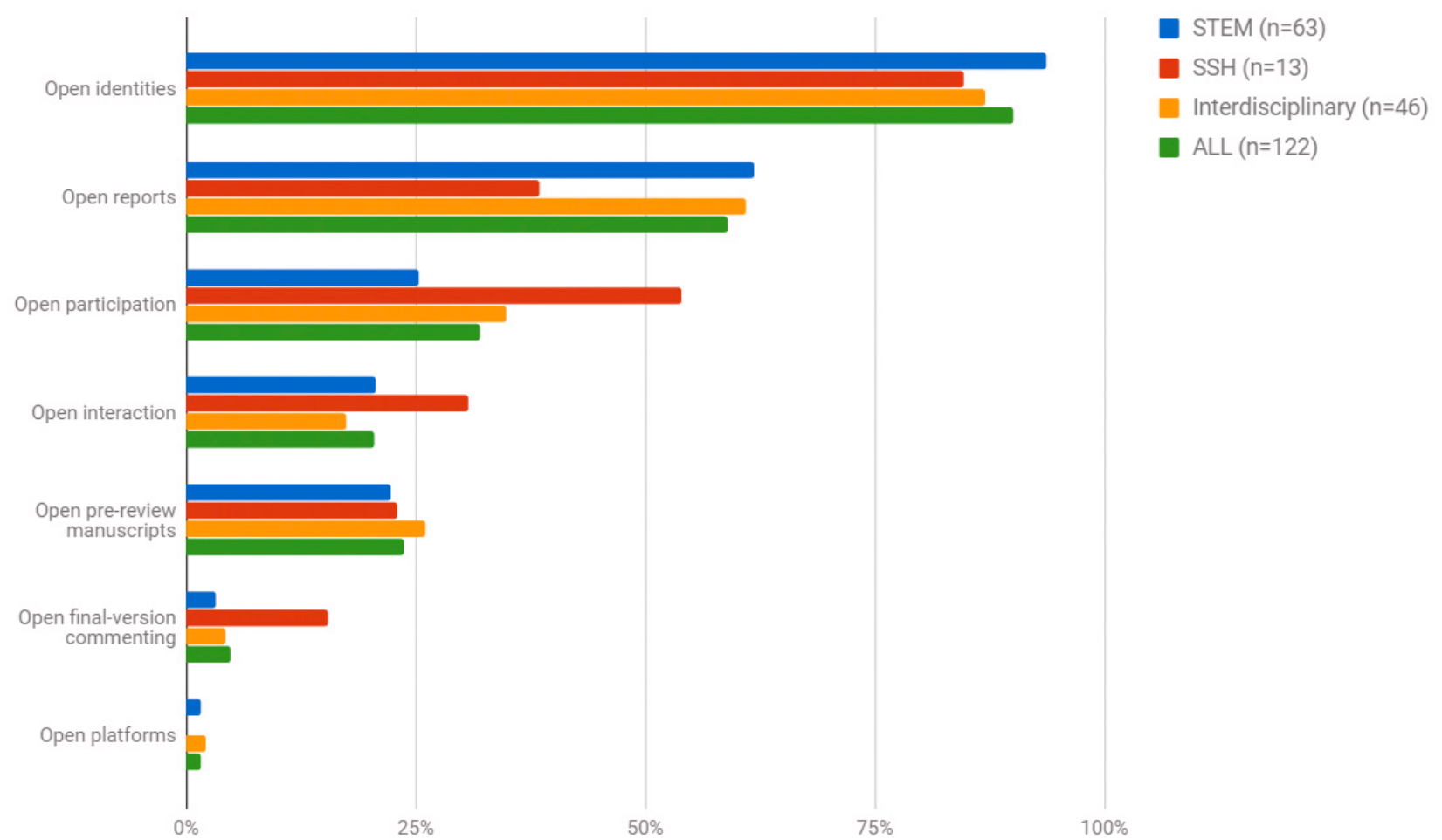

Figure 6. Prevalence of traits (as percentage) within definitions by disciplinary focus of definition. 
in $84.6 \%$ of SSH-focused definitions compared to $93.7 \%$ of STEM-focused definitions) and open reports (38.5\% SSH vs. $61.9 \%$ STEM). Three traits were much more likely to be included in SSH definitions of OPR, however: open participation $(53.85 \% \mathrm{SSH}$ vs. $25.4 \%$ STEM), open interaction (30.8\% SSH vs. $20.6 \%$ STEM), and open final-version commenting (15.4\% SSH vs. 3.2\%STEM). The other traits, open pre-review manuscripts and open platforms, were similar across both groups. Although these differences seem to hint at a slightly different understanding of OPR between the disciplines, we should be careful in generalizing too strongly here. Firstly because splitting scholarship into these two broad groups risks levelling the wealth of disciplinary-specificity within these categories. Secondly, because the number of SSH-specific sources (13) was small.

The various ways these traits are configured within definitions can be seen in Figure 7. Quantifying definitions in this way allows us to accurately portray exactly how ambiguously the phrase "open peer review" has been used thus far, for the literature offers a total of 22 distinct configurations of seven traits, effectively meaning that there are 22 different definitions of OPR in the literature examined here.

The distribution of traits shows two very popular configurations and a variety of rarer ones, with the most popular configuration (open identities) accounting for one third $(33.6 \%, \mathrm{n}=41)$ and the second-most popular configuration (open identities, open reports)

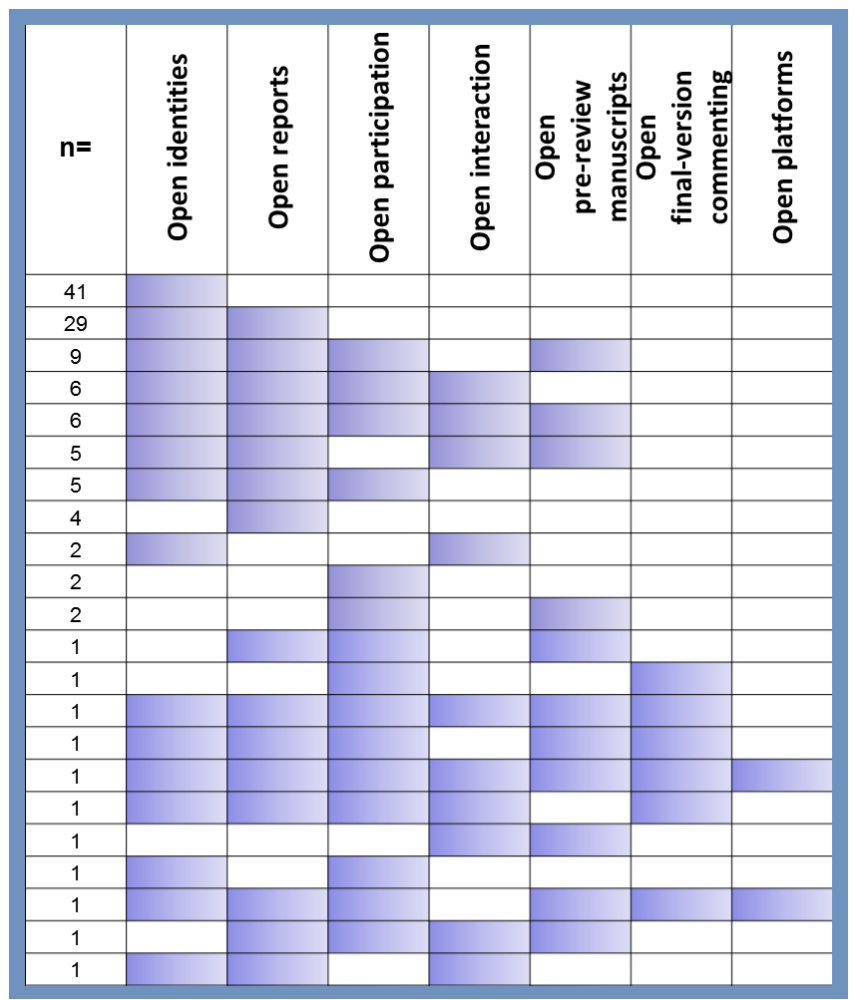

Figure 7. Unique configurations of OPR traits within definitions. accounting for almost a quarter $(23.8 \%, \mathrm{n}=29)$ of all definitions. There then follows a "long-tail" of less-frequently found configurations, with more than half of all configurations being unique to a single definition.

\section{Discussion: The traits of open peer review}

I next offer a detailed analysis of each of these traits, detailing the issues they aim to resolve and the evidence to support their effectiveness.

\section{Open identities}

Open identity peer review, also known as signed peer review (Ford, 2013; Nobarany \& Booth, 2015) and "unblinded review" (Monsen \& Van Horn, 2007), is review where authors and reviewers are aware of each other's identities. Traditional peer review operates as either "single-blind", where authors do not know reviewers' identities, or "double-blind", where both authors and reviewers remain anonymous. Double-blind reviewing is more common in the Arts, Humanities and Social Sciences than it is in STEM (science, technology, engineering and medicine) subjects, but in all areas single-blind review is by far the most common model (Walker \& Rocha da Silva, 2015). A main reason for maintaining author anonymity is that it is assumed to tackle possible publication biases against authors with traditionally feminine names, from less prestigious institutions or non-English speaking regions (Budden et al., 2008; Ross et al., 2006). Reviewer anonymity, meanwhile, is presumed to protect reviewers from undue influence, allowing them to give candid feedback without fear of possible reprisals from aggrieved authors. Various studies have failed to show that such measures increase review quality, however (Fisher et al., 1994; Godlee et al., 1998; Justice et al., 1998; McNutt et al., 1990; van Rooyen et al., 1999). As Godlee and her colleagues have said, "Neither blinding reviewers to the authors and origin of the paper nor requiring them to sign their reports had any effect on rate of detection of errors. Such measures are unlikely to improve the quality of peer review reports" (Godlee et al., 1998). Moreover, factors such as close disciplinary communities and internet search capabilities, mean that author anonymity is only partially effective, with reviewers shown to be able to identify authors in between 26 and 46 percent of cases (Fisher et al., 1994; Godlee et al., 1998).

Proponents of open identity peer review argue that it will enhance accountability, further enable credit for peer reviewers, and simply make the system fairer: "most importantly, it seems unjust that authors should be "judged" by reviewers hiding behind anonymity" (van Rooyen et al., 1999). Open identity peer review is argued, moreover, to potentially increase review quality, as it is theorised that reviewers will be more highly motivated and invest more care in their reviews if their names are attached to them. Finally, a reviewer for this paper advises that "proponents of open identity review in medicine would also point out that it makes conflicts of interest much more apparent and subject to scrutiny" (Bloom, 2017). Opponents counter this by arguing that signing will lead to poorer reviews, as reviewers temper their true opinions to avoid causing offence. To date, studies have failed to show any great effect in either direction (McNutt et al., 1990; van Rooyen et al., 1999; 
van Rooyen et al., 2010). However, since these studies derive from only one disciplinary area (medicine), the results cannot be taken as representative and hence further research is undoubtedly required.

\section{Open reports}

Open reports peer review is where review reports (either full reports or summaries) are published alongside the relevant article. Often, although not in all cases (e.g., EMBO reports, http:// embor.embopress.org), review names are published alongside the reports. The main benefits of this measure lie in making currently invisible but potentially useful scholarly information available for re-use. There is increased transparency and accountability that comes with being able to examine normally behind-the-scenes discussions and processes of improvement and assessment, and a potential to further incentivize peer reviewers by making their peer review work a more visible part of their scholarly activities (thus enabling reputational credit).

Reviewing is hard work. Research Information Network reported in 2008 that a single peer review takes an average of four hours, at an estimated total annual global cost of around $£ 1.9$ billion (Research Information Network, 2008). Once an article is published, however, these reviews usually serve no further purpose than to reside in publisher's long-term archives. Yet those reviews contain information that remains potentially relevant and useful in the here-and-now. Often, works are accepted despite the lingering reservations of reviewers. Published reports can enable readers to consider these criticisms themselves, and "have a chance to examine and appraise this process of "creative disagreement" and form their own opinions" (Peters \& Ceci, 1982). Making reviews public in this way also adds another layer of quality assurance, as the reviews are open to the scrutiny of the wider scientific community. It could also increase review quality, as the thought of their words being made publicly available could motivate reviewers to be more thorough in their review activities. Moreover, publishing reports also aims at raising the recognition and reward of the work of peer reviewers. Adding review activities to the reviewer's professional record is common practice; author identification systems currently also add mechanisms to host such information (e.g. via ORCID) (Hanson et al., 2016). Finally, open reports give young researchers a guide (to tone, length, the formulation of criticisms) to help them as they begin to do peer review themselves.

The evidence-base against which to judge such arguments is not great enough to enable strong conclusions, however. Van Rooyen and her colleagues found that open reports correlate with higher refusal rates amongst potential reviewers, as well as an increase in time taken to write review but no concomitant effect on review quality (van Rooyen et al., 2010). Nicholson and Alperin's small survey, however, found generally positive attitudes: "researchers ... believe that open review would generally improve reviews, and that peer reviews should count for career advancement" (Nicholson \& Alperin, 2016).

\section{Open participation}

Open participation peer review, also known as "crowdsourced peer review" (Ford, 2013; Ford, 2015), "community/public review" (Walker \& Rocha da Silva, 2015) and "public peer review" (Bornmann et al., 2012), allows the wider community to contribute to the review process. Whereas in traditional peer review editors identify and invite specific parties (peers) to review, open participation processes invite interested members of the scholarly community to participate in the review process, either by contributing full, structured reviews or shorter comments. According to Fitzpatrick \& Santo (2012), the rationale for opening up the pool of reviewers in this way is that "fields can often become selfreplicating, as they limit the input that more horizontally-organized peer groups - such as scholars from related disciplines and interdisciplines, and even members of more broadly understood publics - might play in the development of scholarly thought" (Fitzpatrick \& Santo, 2012).

In practice, it may be that comments are open to anybody (anonymous or registered), or some credentials might first be required (e.g., Science Open requires an ORCID profile with at least five published articles). Open participation is often used as a complement to a parallel process of solicited peer review. It aims to resolve possible conflicts associated with editorial selection of reviewers (e.g. biases, closed-networks, elitism) and possibly improve the reliability of peer review by increasing the number of reviewers (Bornmann et al., 2012). Reviewers can come from the wider research community, as well as those traditionally under-represented in scientific assessment, including representatives from industry or members of special-interest groups, for example patients in the case of medical journals (Ware, 2011). This has the potential to open the pool of reviewers beyond those identified by editors to include all potentially interested reviewers (including those from outside academia), and hence increase the number of reviewers for each publication (though in practice this is unlikely). Evidence suggests this practice could help increase the accuracy of peer review. For example, Herron (2012) produced a mathematical model of the peer review process which showed that "the accuracy of public readerreviewers can surpass that of a small group of expert reviewers if the group of public reviewers is of sufficient size", although only if the numbers of reader-reviewers exceeded 50 .

Criticisms of open participation routinely focus on questions about reviewers' qualifications to comment and the incentives for doing so. Given that disciplines are subject to increasingly narrow specialization, especially in the sciences (Casadevall \& Fang, 2014), it can be objected that those who lack intimate knowledge of the particular methods and objects of that field will literarily be unable to properly evaluate findings. As Stevan Harnad has said: "it is not clear whether the self-appointed commentators will be qualified specialists (or how that is to be ascertained). The expert population in any given speciality is a scarce resource, already overharvested by classical peer review, so one wonders who would have the time or inclination to add journeyman commentary services to this load 
on their own initiative" (Harnad, 2000). Here, we might reflect on whether this is one reason why open participation seems to be a more central part of conceptions of OPR in the social science and humanities than in STEM subjects. As we saw above, open participation is actually the second most popular trait in definitions stemming from sources with an SSH-focus, appearing in more than half of those definitions, as compared to just a quarter of definitions that focused specifically on STEM subjects (although, again, we must remind ourselves that the small number of SSH definitions means we should not draw overly-strong conclusions based on this finding). As Fitzpatrick and Santo argue, in the humanities, peer review "often focuses on originality, creativity, depth and cogency of argument, and the ability to develop and communicate new connections across and additions to existing texts and ideas". This is contrasted to the sciences, where peer review is more concretely focused on "verification of results or validation of methodologies" (Fitzpatrick \& Santo, 2012). Assessment of narrative cogency and the interconnection of ideas are more transferable across domains than are knowledge of discipline-specific methods and tools. To be sure, both play a role in all scholarship, but since the former play a larger role in SSH, this may be a motivating factor in increased interest in open participation in those disciplines.

Another issue for open participation is that difficulties have been reported in motivating self-selecting commentators to take part and deliver useful critique. Nature, for example, ran an experiment from June to December 2006 inviting submitting authors to take part in an experiment where open participation would be used as a complement to a parallel process of solicited peer reviews. Nature judged the trial to have been unsuccessful due to the small number of authors wishing to take part (just $5 \%$ of submitting authors), the small number of overall comments (almost half of articles received no comments) and the insubstantial nature of most of the comments that were received (Fitzpatrick, 2011). At the open access journal Atmospheric Chemistry and Physics (ACP), which publishes prereview discussion papers for community comments, only about one in five papers is commented upon (Pöschl, 2012). Bornmann et al. (2012) conducted a comparative content analysis of the ACP's community comments and formal referee reviews and concluded that the latter - tending to focus more on formal qualities, conclusions and potential impact - better supported the selection and improvement of manuscripts. This all suggests that although open participation might be a worthwhile complement to traditional, invited peer review, it is unlikely to be able to fully replace it.

\section{Open interaction}

Open interaction peer review allows and encourages direct reciprocal discussion between reviewers, and/or between author(s) and reviewers. In traditional peer review, reviewers and authors correspond only with editors. Reviewers have no contact with other reviewers, and authors usually have no opportunity to directly question or respond to reviewers' comments. Allowing interaction amongst reviewers or between authors and reviewers, or between reviewers themselves, is another way to "open up" the review process, enabling editors and reviewers to work with authors to improve their manuscript. The motivation for doing so, according to (Armstrong, 1982), is to "improve communication. Referees and authors could discuss difficult issues to find ways to improve a paper, rather than dismissing it". In the words of Kathleen Fitzpatrick (2012), such interaction can foster "a conversational, collaborative discourse that not only harkens back to the humanities' long investment in critical dialogue as essential to intellectual labor, but also models a forward-looking approach to scholarly production in a networked era."

Some journals enable pre-publication interaction between reviewers as standard (Hames, 2014). The EMBO Journal, for example, enables "cross-peer review," where referees are "invited to comment on each other's reports, before the editor makes a decision, ensuring a balanced review process" (EMBO Journal, 2016). At eLife, reviewers and editor engage in an "online consultation session" where they come to a mutual decision before the editor compiles a single peer review summary letter for the author to give them a single, non-contradictory roadmap for revisions (Schekman et al., 2013). The publisher Frontiers has gone a step further, including an interactive collaboration stage that "unites authors, reviewers and the Associate Editor - and if need be the Specialty Chief Editor - in a direct online dialogue, enabling quick iterations and facilitating consensus" (Frontiers, 2016).

Perhaps even more so than other areas studied here, evidence to judge the effectiveness of interactive review is scarce. Based on anecdotal evidence, Walker \& Rocha da Silva (2015) advise that "[r]eports from participants are generally but not universally positive". To the knowledge of the author, the only experimental study that has specifically examined interaction among reviewers or between reviewers and authors is that of Jeffrey Leek and his colleagues, who performed a laboratory study of open and closed peer review based on an online game and found that "improved cooperation does in fact lead to improved reviewing accuracy. These results suggest that in this era of increasing competition for publication and grants, cooperation is vital for accurate evaluation of scientific research" (Leek et al., 2011). Such results are encouraging, but hardly conclusive. Hence, there remains much scope for further research to determine the impact of cooperation on the efficacy and cost of the review process.

\section{Open pre-review manuscripts}

Open pre-review manuscripts are manuscripts that are immediately openly accessible (via the internet) in advance, or in synchrony with, any formal peer review procedures. Subject-specific "preprint servers" like arXiv.org and bioRxiv.org, institutional repositories, catch-all repositories like Zenodo or Figshare and some publisher-hosted repositories (like PeerJ Preprints) allow authors to short-cut the traditional publication process and make their manuscripts immediately available to everyone. This can be used as a complement to a more traditional publication process, with comments invited on preprints and then incorporated into redrafting as the manuscript goes through traditional peer review with a journal. Alternatively, services which overlay peer-review functionalities on repositories can produce functional publication 
platforms at reduced cost (Boldt, 2011; Perakakis et al., 2010). The mathematics journal Discrete Analysis, for example, is an overlay journal whose primary content is hosted on arXiv (Day, 2015). The recently released Open Peer Review Module for repositories, developed by Open Scholar in association with OpenAIRE, is an open source software plug-in which adds overlay peer review functionalities to repositories using the DSpace software (OpenAIRE, 2016). Another innovative model along these lines is that of ScienceOpen, which ingests articles metadata from preprint servers and contextualizes them by adding altmetrics and other relational information, before offering authors peer review.

In other cases, manuscripts are submitted to publishers in the usual way but made immediately available online (usually following some rapid preliminary review or "sanity check") before the start of the peer review process. This approach was pioneered with the 1997 launch of the online journal Electronic Transactions in Artificial Intelligence (ETAI), where a two-stage review process was used. First, manuscripts were made available online for interactive community discussion, before later being subject to standard anonymous peer review. The journal stopped publishing in 2002 (Sandewall, 2012). Atmospheric Chemistry and Physics uses a similar system of multi-stage peer review, with manuscripts being made immediately available as "discussion papers" for community comments and peer review (Pöschl, 2012). Other prominent examples are F1000Research and the Semantic Web Journal.

The benefits to be gained from open pre-review manuscripts is that researchers can assert their priority in reporting findings - they needn't wait for the sometimes seemingly endless peer review and publishing process, during which they might fear being scooped. Moreover, getting research out earlier increases its visibility, enables open participation in peer review (where commentary is open to all), and perhaps even, according to (Pöschl, 2012), increases the quality of initial manuscript submissions. Finally, making manuscripts openly available in advance of review allows comments to be posted as they are received, either from invited reviewers or the wider community, and enabling readers to follow the process of peer-review in real-time.

\section{Open final-version commenting}

Open final-version commenting is review or commenting on final "version of record" publications. If the purpose of peer review is to assist in the selection and improvement of manuscripts for publication, then it seems illogical to suggest that peer review can continue once the final version-of-record is made public. Nonetheless, in a literal sense, even the declared fixed version-of-record continues to undergo a process of improvement (occasionally) and selection (perpetually).

The internet has hugely expanded the range of effective action available for readers to offer their feedback on scholarly works. Where before only formal routes like the letters to the journal or commentary articles offered readers a voice, now a multitude of channels exist. Journals are increasingly offering their own commentary sections. Walker \& Rocha da Silva (2015) found that of 53 publishing venues reviewed, 24 provided facilities to enable user-comments on published articles - although these were typically not heavily used. Researchers seem to see the worth of such functionalities, with almost half of respondents to a 2009 survey believing supplementing peer review with some form of post-publication commentary to be beneficial (Mulligan et al., 2013). But users can "publish" their thoughts anywhere on the Web - via academic social networks like Mendeley, ResearchGate and Academia. edu, via Twitter, or on their own blogs. In this sense, peer review can be decoupled not only from the journal, but also from any particular platform. The reputation of a piece of work is continuously evolving as long as it remains the subject of discussion. Thus, considering final-version commenting to be an active part of an ongoing, perpetual process peer review in a wider sense hence might encourage an adjustment in our conception of the nature of peer review, away from seeing it as a distinct process that leads to publication, and Improvements based on feedback happen most obviously in the case of so-called 'living' publications, like the Living Reviews group of three disciplinary journals in the fields of relativity, solar physics and computational astrophysics, publishing invited review articles which allow authors to regularly update their articles to incorporate the latest developments in the field. Here, even where the published version is anticipated to be the final version, it remains open to future retraction or correction. Such changes are often fueled by social media, as in the 2010 case of \#arseniclife, where social media critique over flaws in the methodology of a paper claiming to show a bacterium capable of growing on arsenic resulted in refutations being published in Science. The Retraction Watch blog is dedicated to publicizing such cases.

An important platform in this regard has been Pubpeer which proclaims itself a "post-publication peer review platform". When its users swarmed to critique a Nature paper on STAP (StimulusTriggered Acquisition of Pluripotency) cells, PubPeer argued that its "post-publication peer review easily outperformed even the most careful reviewing in the best journal. The papers' comment threads on PubPeer have attracted some 40000 viewers. It's hardly surprising they caught issues that three overworked referees and a couple of editors did not. Science is now able to self-correct instantly. Post-publication peer review is here to stay" (PubPeer, 2014).

\section{Open platforms ("decoupled review")}

Open platforms peer review is review facilitated by a different organizational entity than the venue of publication. Recent years have seen the emergence of a group of dedicated platforms which aim to augment the traditional publishing ecosystem by de-coupling review functionalities from journals. Services like RUBRIQ and Peerage of Science offer "portable" or "independent" peer review. A similar service, Axios Review, operated from 2013 to 2017. Each platform invites authors to submit manuscripts directly to them, then organises review amongst their own community of reviewers and returns review reports. In the case of RUBRIQ and Peerage 
of Science, participating journals then have access to these scores and manuscripts and so can contact authors with a publishing offer or to suggest submission. Axios meanwhile, directly forwarded the manuscript, along with reviews and reviewer identities, to the author's preferred target journal. The models vary in their details RUBRIQ, for example, pays its reviewers, whereas Axios operated on a community model where reviewers earned discounts on having their own work reviewed - but all aim in their ways to reduce inefficiencies in the publication process, especially the problem of duplication of effort. Whereas in traditional peer review, a manuscript could undergo peer review at several journals, as it is submitted and rejected, then submitted elsewhere, such services need just one set of reviews which can be carried over to multiple journals until a manuscript finds a home (hence "portable" review).

Other decoupled platforms aim at solving different problems. Publons seeks to address the problem of incentive in peer review by turning peer review into measurable research outputs. Publons collects information about peer review from reviewers and publishers to produce reviewer profiles which detail verified peer review contributions that researchers can add to their CVs. Overlay journals like Discrete Mathematics, discussed above, are another example of open platforms. Peter Suber (quoted in Cassella \& Calvi, 2010) defines the overlay journal as "An open-access journal that takes submissions from the preprints deposited at an archive (perhaps at the author's initiative), and subjects them to peer review... Because an overlay journal doesn't have its own apparatus for disseminating accepted papers, but uses the pre-existing system of interoperable archives, it is a minimalist journal that only performs peer review." Finally, there are the many venues through which readers can now comment on already-published works (see also "open final-version commenting" above), including blogs and social networking sites, as well as dedicated platforms such as PubPeer.

\section{Which problems with traditional peer do the various OPR} traits address?

I began by sketching out various problems with traditional peer review and advised that OPR, in its various incarnations, has been proposed as a solution to many of these problems, but that no individual trait addresses all of these problems, and that sometimes their aims may be in conflict. Which traits address which of the problems identified above? Which might actually exacerbate them? Based on the foregoing, I here present this summary:

- Unreliability and inconsistency: Open identities and open reports are theorized to lead to better reviews, as the thought of having their name publicly connected to a work or seeing their review published encourages reviewers to be more thorough. There is at present too little evidence to judge if this is actually so, however. Open participation and open finalversion commenting are theorized to possibly improve the reliability of peer review by increasing the number of potential reviewers, especially from different disciplinary backgrounds. In practice, open participation struggles to attract reviewers in most cases and thus is probably not a sustainable replacement for invited peer review, although it is perhaps a worthwhile supplement to it. Some evidence suggests that open interaction between reviewers and authors could lead to improved reviewing accuracy.

- Delay and expense: Open pre-review manuscripts sharply reduce the time before research is first publicly available and may increase the overall quality of initial submissions. Open platforms can help overcome the "waterfall" problem, where individual articles go through multiple cycles of review and rejection at different journals. In principle, open participation could reduce the need for editorial mediation in finding reviewers, but in practice any reduction of costs is questionable, as open participation can fail to attract reviewers and in any case, editorial mediation will continue to be necessary to facilitate discussion and arbitrate disputes. Open identities and open reports might actually exacerbate problems of delay and expense, as it seems invited reviewers are currently less inclined to review under such circumstances. Finally, open interaction - by necessitating more back and forth between reviewers and authors, and more editorial mediation - might lead to longer reviewing times.

- Lack of accountability and risks of subversion: Open identities and reports can increase accountability through increased transparency and by making any conflicts of interest more immediately apparent to authors and future readers. Open participation could overcome problems associated with editorial selection of reviewers (e.g. biases, closed-networks, elitism). However, in opening up participation to the wider community, it might actually increase engagement by those with conflicts of interest. Where anonymity is possible, this may be particularly problematic. Moreover, lack of anonymity for reviewers in open identities review might subvert the process by discouraging reviewers from making strong criticisms, especially against higher-status colleagues.

- Social and publication biases: Open reports adds another layer of quality assurance, allowing the wider community to scrutinize reviews to examine decision-making processes. However, open identities removes anonymity conditions for reviewers (single-blind) or authors and reviewers (doubleblind) which are traditionally in place to counteract social biases (although there is not strong-evidence that such anonymity has been effective).

- Lack of incentives: Open reports linked to open identities enable higher visibility for peer review activities, allowing review work to be cited in other publications and in career development activities linked to promotion and tenure. Open participation could in principle increase incentives to peer review by enabling reviewers to themselves select the works that they consider themselves qualified to judge; however in practice, experience to date suggests that reviewers are less likely to review under this condition. 
- Wastefulness: Open reports make currently invisible but potentially useful scholarly information available for re-use, as well as providing young researchers a guide (to tone, length, the formulation of criticisms) to help them as they begin to do peer review themselves.

This synthesis allows us to draw the following conclusions: (1) the individual traits of OPR can be argued to address many of the problems with traditional peer review, but (2) differing traits addresses differing problems in differing ways, (3) no trait addresses all problems, and in fact (4) individual traits may actually exacerbate problems in some areas. Assessing this already complex landscape is made yet more problematic by the fact that (5) there is often little evidence to support or challenge many of these claims. There is hence a pressing need for more research to empirically evaluate the efficacy of differing traits in resolving these issues.

Open Science as the unifying theme for the traits of OPR The traits that we have identified to be part of definitions of OPR are disparate in their aims and implementation. Is there any common thread between them? I would argue yes: they each aim to bring peer review more into line with the emergent agenda of Open Science. To advance this argument, I'll next briefly describe this movement and its underlying aims, and then relate each OPR trait to this agenda.

Open Science is the name given to a broad movement to reshape scholarly communication. As the English word "science" traditionally excludes the humanities and social sciences, the phenomenon is often referred to by more explicitly inclusive terms like "open scholarship" or "open research". As "Open Science" is the more common term, I shall use it here, but should be read as referring to research from all academic disciplines.

Open Science encompasses a variety of practices, usually including areas like open access to publications, open research data, open source software/tools, open workflows, citizen science, open educational resources, and alternative methods for research evaluation including open peer review (Pontika et al., 2015). The aims and assumptions underlying the push to implement these various practices have been analysed by Fecher \& Friesike (2013), whose analysis of the literature found five broad concerns, or "schools of thought" (Figure 8). These are:

- Democratic school: Believing that there is an unequal distribution of access to knowledge, this area is concerned with

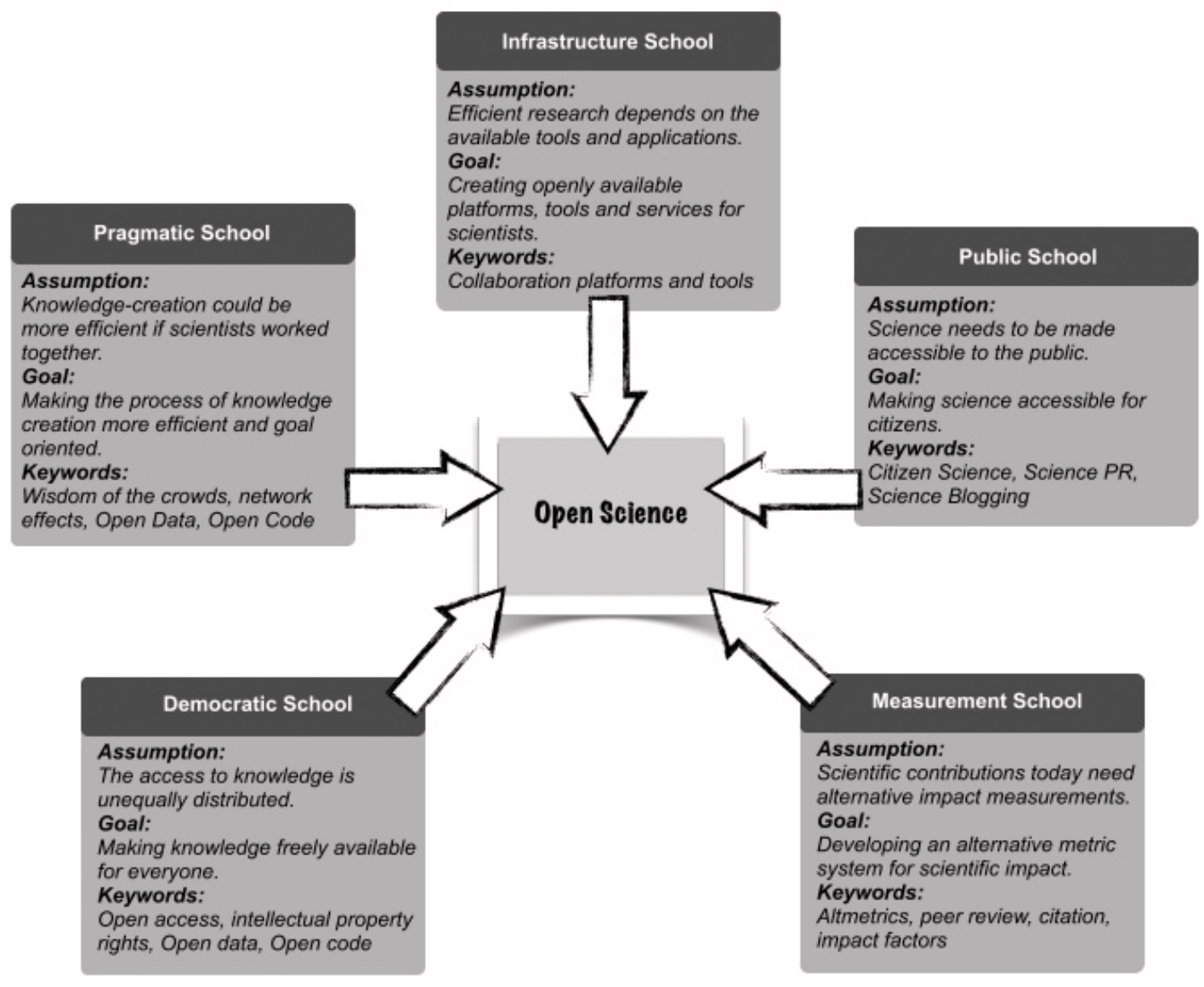

Figure 8. Five schools of thought in Open Science (CC BY-NC, Fecher \& Friesike, 2013).

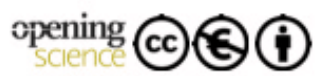


making scholarly knowledge (including publications and data) available freely for all.

- Pragmatic school: Following the principle that the creation of knowledge is made more efficient through collaboration and strengthened through critique, this area seeks to harness network effects by connecting scholars and making scholarly methods transparent.

- Infrastructure school: This thread is motivated by the assumption that efficient research requires readily available platforms, tools and services for dissemination and collaboration.

- Public school: Based on the recognition that true societal impact requires societal engagement in research and readily understandable communication of scientific results, this area seeks to bring the public to collaborate in research through citizen science, and make scholarship more readily understandable through lay summaries, blogging and other less formal communicative methods.

- Measurement school: Motivated by the acknowledgement that traditional metrics for measuring scientific impact have proven problematic (by being too heavily focused on publications, often only at the journal-level, for instance), this strand seeks "alternative metrics" which can make use of the new possibilities of digitally networked tools to track and measure the impact of scholarship through formerly invisible activities.

The traits of OPR, in differing yet overlapping ways, each aim to bring greater transparency, accountability, inclusivity and/or efficiency to the restricted model of traditional peer review. The traits of OPR can be fit into Fecher \& Friesike's Open Science schema thus:

- Democratic school: Open reports further make scholarly products available to all.

- Pragmatic school: Open identities foster increased accountability by linking scholars' names to their judgements; open reports increases transparency by opening review reports to readers; open interaction fosters increased collaboration between authors, reviewers and editors in the process of evaluation and revision of scholarship; open pre-review manuscripts enable the earlier dissemination of results.

- Infrastructure school: Open platforms can make peer review more efficient by decoupling it from journals.

- Public school: Open participation and final-version commenting bring greater inclusivity to peer review by expanding the potential pool of reviewers, including to those outside traditional research actors.

- Measurement school: Open identities, open reports and open platforms (e.g., Publons) enable peer review activities to be more clearly monitored and taken into account in impactmeasurement activities.

\section{Conclusion}

We have seen that the definition of "open peer review" is contested ground. My aim here has been to provide some clarity as to what is being referred to when this term is used. This is especially important since interest in the term (measured via references in the literature) is growing rapidly. By analyzing 122 separate definitions from the literature I have identified seven different traits of OPR, which all aim to resolve differing problems with traditional peer review. Amongst the corpus of definitions there are 22 unique configurations of these traits, meaning 22 distinct definitions of OPR in the reviewed literature. Across all definitions, the core elements are open identities and open reports, with one or both elements present in over $95 \%$ of the definitions examined. Among the other elements, open participation is the next most common element, and should perhaps be considered a core trait in SSH. Further secondary elements are open interaction and pre-review manuscripts. Fringe elements include open final version commenting and open platforms.

Given that OPR is such a contested concept, in my view the only sensible way forward is to acknowledge the ambiguity of this term, accepting that it is used as an umbrella concept for a diverse array of peer review innovations. Although it could be argued that merely accepting the status quo in this way does not help resolve possible confusion regarding usage, I would argue that quantifying the ambiguity of usage and mapping the distinct traits enables future discussion to start from a firmer basis that (1) acknowledges that people often mean different things when they use this term, and (2) clarifies in advance exactly which OPR traits are under discussion.

By being clear about these distinct traits, it will enable us to treat the ambiguity of OPR as a feature and not a bug. The large number of possible configurations of options presents a tool-kit for differing communities to construct open peer review systems that reflect their own needs, preferences and goals. The finding that there seems to be a difference in interpretations between disciplines (for example, that open participation seems more central to conceptions of OPR in SSH than STEM) reinforces this view. Moreover, disambiguating these traits will enable more focused analysis of the extent to which these traits are actually effective in countering the problems they are claimed to address. This is particularly urgent because, as we have seen, there is often little evidence to support or refute many of these claims. 
Based upon this analysis I offer the following definition:

OPR definition: Open peer review is an umbrella term for a number of overlapping ways that peer review models can be adapted in line with the aims of Open Science, including making reviewer and author identities open, publishing review reports and enabling greater participation in the peer review process. The full list of traits is:

- Open identities: Authors and reviewers are aware of each other's identity

- Open reports: Review reports are published alongside the relevant article.

- Open participation: The wider community to able to contribute to the review process.

- Open interaction: Direct reciprocal discussion between author(s) and reviewers, and/or between reviewers, is allowed and encouraged.

- Open pre-review manuscripts: Manuscripts are made immediately available (e.g., via pre-print servers like arXiv) in advance of any formal peer review procedures.

- Open final-version commenting: Review or commenting on final "version of record" publications.

- Open platforms ("decoupled review"): Review is facilitated by a different organizational entity than the venue of publication.
Data availability

Dataset including full data files used for analysis in this review: http://doi.org/10.5281/zenodo.438024 (Ross-Hellauer, 2017).

\section{Competing interests}

This work was conducted as part of the OpenAIRE2020 project, an EC-funded initiative to implement and monitor Open Access and Open Science policies in Europe and beyond.

\section{Grant information}

This work is funded by the European Commission H2020 project OpenAIRE2020 (Grant agreement: 643410, Call: H2020-EINFRA2014-1).

The funders had no role in study design, data collection and analysis, decision to publish, or preparation of the manuscript.

\section{Acknowledgements}

The author thanks Birgit Schmidt (University of Goettingen), Arvid Deppe (University of Kassel), Jon Tennant (Imperial College London, ScienceOpen), Edit Gorogh (University of Goettingen) and Alessia Bardi (Istituto di Scienza e Tecnologie dell'Informazione) for discussion and comments that led to the improvement of this text. Birgit Schmidt created Figure 1.

\title{
Supplementary material
}

Supplementary file 1: PRISMA checklist. The checklist was completed with the original copy of the manuscript.

Click here to access the data.

\section{Supplementary file 2: PRISMA flowchart showing the number of records identified, included and excluded.}

\author{
Click here to access the data.
}

Armstrong JS: Barriers to Scientific Contributions: The Authors Formula. Behav Brain Sci. Cambridge University Press (CUP). 1982; 5(02): 197-199. Publisher Full Text

Armstrong JS: Peer Review for Journals: Evidence on Quality Control Fairness, and Innovation. Sci Eng Ethics. Springer Nature. 1997; 3(1): 63-84. Publisher Full Text

Bardy AH: Bias in reporting clinical trials. Br J Clin Pharmacol. Wiley-Blackwell. 1998; 46(2): 147-50.

PubMed Abstract | Publisher Full Text | Free Full Text

Bloom T: Referee Report For: What is open peer review? A systematic review [version 1; referees: 1 approved, 3 approved with reservations]. F1000Res.

2017; 6: 588.

Publisher Full Text

Boldt A: Extending ArXiv.Org to Achieve Open Peer Review and Publishing.
J Scholarly Publ. University of Toronto Press Inc. (UTPress), 2011; 42(2): 238-42. Publisher Full Text

Bornmann L, Herich H, Joos H, et al.: In Public Peer Review of Submitted Manuscripts How Do Reviewer Comments Differ from Comments Written by Interested Members of the Scientific Community? A Content Analysis of Comments Written for Atmospheric Chemistry and Physics. Scientometrics. Springer Nature. 2012; 93(3): 915-29.

Publisher Full Text

Budden AE, Tregenza T, Aarsen LW, et al: Double-blind review favours increased representation of female authors. Trends Ecol Evol. 2008; 23(1): 4-6. PubMed Abstract | Publisher Full Text

Campanario JM: Peer Review for Journals as It Stands Today-Part 1. Sci Commun. SAGE Publications. 1998; 19(3): 181-211.

Publisher Full Text 
Casadevall A, Fang FC: Specialized science. Infect Immun. 2014; 82(4): $1355-1360$.

PubMed Abstract | Publisher Full Text | Free Full Text

Cassella M, Calvi L: New Journal Models and Publishing Perspectives in the Evolving Digital Environment. IFLA Journal. SAGE Publications. 2010; 36(1): 7-15.

Publisher Full Text

Chubin DE, Hackett EJ: Peerless Science: Peer Review and US Science Policy. Suny Press, 1990.

Reference Source

Cronin B: Vernacular and Vehicular Language. J Am Soc Inf Sci Technol.

Wiley-Blackwell. 2009; 60(3): 433.

Publisher Full Text

Dall'Aglio P: Peer Review and Journal Models. ArXiv:Physics/0608307, 2006.

Reference Source

Daniel HD: Guardians of Science. Wiley-Blackwell, 1993.

Publisher Full Text

Day C: Meet the Overlay Journal. Phys Today. AIP Publishing, 2015.

Publisher Full Text

Dickersin K, Min YI, Meinert CL: Factors influencing publication of research results. Follow-up of applications submitted to two institutional review boards.

JAMA. American Medical Association (AMA). 1992; 267(3): 374-8.

PubMed Abstract | Publisher Full Text

EMBO Journal: About |The EMBO Journal [WWW Document]. 2016; (accessed 8.24.16).

Reference Source

Ernst E, Kienbacher T: Chauvinism. Nature. Springer Nature. 1991; 352(6336): 560.

Publisher Full Text

Fanelli D: Do Pressures to Publish Increase Scientists' Bias? An Empirical Support from US States Data. Edited by Enrico Scalas. PLoS One. Public Library of Science (PLoS). 2010; 5(4): e10271.

PubMed Abstract | Publisher Full Text | Free Full Text

Fang FC, Casadevall A: Retracted Science and the Retraction Index. Infect

Immun. American Society for Microbiology. 2011; 79(10): 3855-59.

PubMed Abstract | Publisher Full Text | Free Full Text

Fang FC, Steen RG, Casadevall A: Misconduct Accounts for the Majority of Retracted Scientific Publications. Proc Natl Acad Sci U S A. Proceedings of the National Academy of Sciences. 2012; 109(42): 17028-33.

PubMed Abstract | Publisher Full Text | Free Full Text

Fecher B, Friesike S: Open Science: One Term, Five Schools of Thought. In: Bartling, S. and Friesike (Eds.), Opening Science. New York, NY: Springer, 2013; $17-47$.

Publisher Full Text

Fisher M, Friedman SB, Strauss B: The Effects of Blinding on Acceptance of Research Papers by Peer Review. JAMA. American Medical Association (AMA). 1994; 272(2): 143-46.

PubMed Abstract | Publisher Full Text

Fitzpatrick K: Planned Obsolescence. New York, NY: NYU Press, 2011. Reference Source

Fitzpatrick K, Santo A: Open Review, A Study of Contexts and Practices. Report. 2012

Reference Source

Ford E: Defining and Characterizing Open Peer Review: A Review of the Literature. J Scholarly Publ. University of Toronto Press Inc. (UTPress), 2013; 44(4): 311-26.

Publisher Full Text

Ford E: Open peer review at four STEM journals: an observational overview [version 2; referees: 2 approved, 2 approved with reservations]. F1000Res.

F1000 Research Ltd. 2015; 4: 6.

PubMed Abstract | Publisher Full Text | Free Full Text

Frontiers: About Frontiers Academic Journals and Research Community. 2016 Reference Source

Garcia JA, Rodriguez-Sanchez R, Fdez-Valdivia J: Authors and Reviewers Who Suffer from Confirmatory Bias. Scientometrics. Springer Nature. 2016; 109(2): 1377-95.

Publisher Full Text

Gillespie GW, Chubin DE, Kurzon GM: Experience with NIH Peer Review: Researchers Cynicism and Desire for Change. Sci Technol Hum Val. 1985; 10(3): $44-54$.

Publisher Full Tex

Godlee F, Gale CR, Martyn CN: Effect on the quality of peer review of blinding reviewers and asking them to sign their reports: a randomized controlled trial. JAMA. American Medical Association (AMA). 1998; 280(3): 237-40. PubMed Abstract | Publisher Full Text

Hames I: The Changing Face of Peer Review. Sci Ed. Korean Council of Science Editors. 2014; 1(1): 9-12.

Publisher Full Text

Hanson B, Lawrence R, Meadows A, et al:: Early Adopters of ORCID

Functionality Enabling Recognition of Peer Review: Two Brief Case Studies.

Learn Publ. Wiley-Blackwell. 2016; 29(1): 60-63.

Publisher Full Text

Harnad S: The Invisible Hand of Peer Review. Journal (On-line/Unpaginated).
Exploit Interactive. 2000

Reference Source

Herron DM: Is expert peer review obsolete? A model suggests that postpublication reader review may exceed the accuracy of traditional peer review. Surg Endosc. Springer Nature. 2012; 26(8): 2275-80.

PubMed Abstract | Publisher Full Text

loannidis JP: Effect of the statistical significance of results on the time to completion and publication of randomized efficacy trials. JAMA. American Medical Association (AMA). 1998; 279(4): 281-6.

PubMed Abstract | Publisher Full Text

Janowicz K, Hitzler P: Open and Transparent: the Review Process of the Semantic Web Journal. Learn Publ. Wiley-Blackwell. 2012; 25(1): 48-55. Publisher Full Text

Jubb M: Peer Review: The Current Landscape and Future Trends. Learn Publ. Wiley-Blackwell. 2016; 29(1): 13-21.

Publisher Full Text

Justice AC, Cho MK, Winker MA, et al:: Does masking author identity improve peer review quality? A randomized controlled trial. PEER Investigators. JAMA. American Medical Association (AMA). 1998; 280(3): 240-2.

PubMed Abstract | Publisher Full Text

Kaplan S: Major Publisher Retracts 64 Scientific Papers in Fake Peer Review Outbreak. Washington Post, 2015.

Reference Source

Kerr S, Tolliver J, Petree D: Manuscript Characteristics Which Influence Acceptance for Management and Social Science Journals. Acad Manage J. The Academy of Management. 1977; 20(1): 132-41.

Publisher Full Text

Kravitz RL, Franks P, Feldman MD, et al.: Editorial peer reviewers'

recommendations at a general medical journal: are they reliable and do editors care? PLoS One. Public Library of Science (PLoS). 2010; 5(4): e10072. PubMed Abstract | Publisher Full Text | Free Full Text

Kriegeskorte N: Open evaluation: a vision for entirely transparent postpublication peer review and rating for science. Front Comput Neurosci. Frontiers Media SA. 2012; 6: 79

PubMed Abstract | Publisher Full Text | Free Full Text

Leek JT, Taub MA, Pineda FJ: Cooperation between referees and authors increases peer review accuracy. PLoS One. Public Library of Science (PLOS) 2011; 6(11): e26895.

PubMed Abstract | Publisher Full Text | Free Full Text

Link AM: US and non-US submissions: an analysis of reviewer bias. JAMA. 1998; 280(3): 246-7.

PubMed Abstract | Publisher Full Text

Lloyd ME: Gender factors in reviewer recommendations for manuscript publication. J Appl Behav Anal. Society for the Experimental Analysis of Behavior 1990; 23(4): 539-43.

PubMed Abstract | Free Full Text

Mahoney MJ: Publication Prejudices: An Experimental Study of Confirmatory Bias in the Peer Review System. Cognit Ther Res. 1977; 1(2): Springer Nature: 161-75.

Publisher Full Text

McNutt RA, Evans AT, Fletcher RH, et al: The effects of blinding on the quality of peer review. A randomized trial. JAMA. American Medical Association (AMA) 1990; 263(10): 1371-6.

PubMed Abstract | Publisher Full Text

Monsen ER, Van Horn L: Research: Successful Approaches. American Dietetic Association; 2007.

Reference Source

Moore S, Neylon C, Eve MP, et al.: Excellence R Us: University Research and the Fetishisation of Excellence. Palgrave Commun. Springer Nature. 2017; 3 16105.

Publisher Full Text

Mulligan A, Hall L, Raphael E: Peer Review in a Changing World: An International Study Measuring the Attitudes of Researchers. J Am Soc Inf Sci Technol. Wiley-Blackwell. 2013; 64(1): 132-61.

Publisher Full Text

Nicholson J, Alperin JP: A Brief Survey on Peer Review in Scholarly Communication. The Winnower, 2016.

Reference Source

Nickerson RC, Varshney U, Muntermann J: A Method for Taxonomy Development and Its Application in Information Systems. Eur J Inf Syst. Springer Nature. 2013; 22(3): 336-59

Publisher Full Text

Nobarany S, Booth KS: Use of Politeness Strategies in Signed Open Peer Review. J Assoc Inf Sci Technol. Wiley-Blackwell. 2015; 66(5): 1048-64. Publisher Full Text

OpenAIRE: OpenAIRE's Experiments in Open Peer Review / Report. Zenodo. 2016 Publisher Full Text

Perakakis P, Taylor M, Mazza M, et al:: Natural Selection of Academic Papers. Scientometrics. Springer Nature. 2010; 85(2): 553-59.

Publisher Full Text

Peters DP, Ceci SJ: Peer-Review Practices of Psychological Journals: The Fate of Published Articles Submitted Again. Behav Brain Sci. Cambridge University Press (CUP). 1982; 5(02): 187-195.

Publisher Full Text 
Pontika N, Knoth P, Cancellieri M, et al.: Fostering Open Science to Research Using a Taxonomy and an ELearning Portal. In Proceedings of the 15th International Conference on Knowledge Technologies and Data-Driven Business - i-KNOW 15. Association for Computing Machinery (ACM). 2015. Publisher Full Text

Pöschl U: Multi-stage open peer review: scientific evaluation integrating the strengths of traditional peer review with the virtues of transparency and self-regulation. Front Comput Neurosci. Frontiers Media SA. 2012; 6: 33. PubMed Abstract | Publisher Full Text | Free Full Text

PubPeer: Science Self-Corrects - Instantly. PubPeer: The Online Journal Club. 2014. Reference Source

Research Information Network: Activities, Costs and Funding Flows in the Scholarly Communications System in the UK: Report Commissioned by the Research Information Network (RIN). 2008.

Reference Source

Ross JS, Gross CP, Desai MM, et al.: Effect of blinded peer review on abstract acceptance. JAMA. American Medical Association (AMA). 2006; 295(14): 1675-80. PubMed Abstract | Publisher Full Text

Ross-Hellauer T: Review of Definitions of Open Peer Review in the Scholarly Literature 2016. 2017.

Data Source

Sandewall E: Maintaining Live Discussion in Two-Stage Open Peer Review.

Front Comput Neurosci. Frontiers Media SA. 2012; 6: 9 .

PubMed Abstract | Publisher Full Text | Free Full Text

Schekman R, Watt F, Weigel D: The eLife approach to peer review. eLife. eLife

Sciences Organisation Ltd. 2013; 2: e00799.

PubMed Abstract | Publisher Full Text | Free Full Text

Schroter S, Black N, Evans S, et al:: Effects of Training on Quality of Peer

Review: Randomised Controlled Trial. BMJ. BMJ. 2004; 328(7441): 673-70.

PubMed Abstract | Publisher Full Text | Free Full Text

Smith R: Peer review: a flawed process at the heart of science and journals.

$J$ R Soc Med. SAGE Publications. 2006; 99(4): 178-82.

PubMed Abstract | Free Full Text

Spier R: The History of the Peer-Review Process. Trends Biotechnol. Elsevier BV. 2002; 20(8): 357-58.

PubMed Abstract | Publisher Full Text
Steen RG, Casadevall A, Fang FC: Why has the number of scientific retractions increased? Edited by Gemma Elizabeth Derrick. PLoS One. Public Library of Science (PLoS). 2013; 8(7): e68397.

PubMed Abstract | Publisher Full Text | Free Full Text

Suber P: Open Access. Cambridge, MA: MIT Press, 2012.

Reference Source

Tennant JP, Dugan JM, Graziotin D, et al:: A multi-disciplinary perspective on emergent and future innovations in peer review [version 1; referees: 2 approved with reservations]. F1000Res. 2017; 6: 1151

Publisher Full Text

Travis GD, Collins HM: New Light on Old Boys: Cognitive and Institutional Particularism in the Peer Review System. Sci Technol Hum Val. 1991; 16(3). Publisher Full Text

Tregenza T: Gender Bias in the Refereeing Process? Trends Ecol. 2002; 17(8): 349-350.

Publisher Full Text

van Rooyen S, Delamothe T, Evans SJ: Effect on peer review of telling reviewers that their signed reviews might be posted on the web: randomised controlled trial. BMJ. BMJ. 2010; 341: c5729.

PubMed Abstract | Publisher Full Text | Free Full Text

van Rooyen S, Godlee F, Evans S, et al:: Effect of open peer review on quality of reviews and on reviewers' recommendations: a randomised trial. BMJ. BMJ. 1999; 318(7175): 23-27.

PubMed Abstract | Publisher Full Text | Free Full Text

Walker R, Rocha da Silva P: Emerging trends in peer review-a survey. Front

Neurosci. Frontiers Media SA. 2015; 9: 169

PubMed Abstract | Publisher Full Text | Free Full Tex

Ware M: Peer Review: Benefits, Perceptions and Alternatives. Publishing

Research Consortium 4, 2008.

Reference Source

Ware M: Peer Review: Recent Experience and Future Directions. New Review of Information Networking. Informa UK Limited. 2011; 16(1): 23-53.

Publisher Full Text

Ware M: Peer Review Survey 2015. Publishing Research Consortium

2016.

Reference Source 


\section{Open Peer Review}

\section{Current Peer Review Status:}

\section{Version 2}

Reviewer Report 10 October 2017

https://doi.org/10.5256/f1000research.13517.r25574

(C) 2017 Mehmani B. This is an open access peer review report distributed under the terms of the Creative Commons Attribution License, which permits unrestricted use, distribution, and reproduction in any medium, provided the original work is properly cited.

\section{Bahar Mehmani}

Global Publishing Development department, Elsevier, RELX Group, Amsterdam, The Netherlands I read the new version and confirm all my comments to the original version are now addressed properly in the article.

I have no further comments and approve the current version of the article.

Competing Interests: No competing interests were disclosed.

I confirm that I have read this submission and believe that I have an appropriate level of expertise to confirm that it is of an acceptable scientific standard.

Reviewer Report 04 October 2017

\section{https://doi.org/10.5256/f1000research.13517.r25576}

(C) 2017 Bloom T. This is an open access peer review report distributed under the terms of the Creative Commons Attribution License, which permits unrestricted use, distribution, and reproduction in any medium, provided the original work is properly cited.

\section{Theodora Bloom}

The BMJ, London, UK

I commend the author for a thorough revision of the manuscript in the light of reviewers' comments.

I had three significant concerns previously. The first was about methodology, and the author has addressed this with more details and description of the method. The second concerned omitting mention of 'real time peer review in the open' as an option, and including 'open platforms'. 
Realtime open review is now mentioned. Open platforms are retained, but it is mentioned that they are an unusual (or 'fringe') case of the meaning of open peer review. The final major concern was about conflating editorial selection with peer review, and the author has now nicely clarified this distinction.

My more minor concerns have also all been addressed.

Competing Interests: I am a full-time journal editor, employed by The BMJ which does research in this area (and is cited in the article)

Reviewer Expertise: I am a journal editor. I have operated a couple of different variants of open peer review.

\section{I confirm that I have read this submission and believe that I have an appropriate level of expertise to confirm that it is of an acceptable scientific standard.}

Reviewer Report 26 September 2017

https://doi.org/10.5256/f1000research.13517.r25575

(C) 2017 Ford E. This is an open access peer review report distributed under the terms of the Creative Commons Attribution License, which permits unrestricted use, distribution, and reproduction in any medium, provided the original work is properly cited.

\section{Emily Ford}

Urban \& Public Affairs Librarian, Portland State University, Portland, OR, USA

I commend the author on the edits and revisions to this article. They have strengthened the work. The expansion of the methods section, as well as the new figure and additional language discussing differences between STEM and SSH disciplines enhances this article and situates it for broader, cross-disciplinary discussion and impact. Further, these revisions have allowed the author to articulate areas for further study.

These revisions have addressed the majority of my previous comments. Those comments that were not address by the revisions pertaining to disciplinary economic disparities introduced by article processing charges as well as further delving into differences between STEM and SSH disciplines, are out of scope for this article. Related to the article's discussion of the "wastefulness" of traditional peer review models, my hope is that this thread, which introduces and discusses areas for future research along this vein, is captured in the scholarly conversation and written record.

Competing Interests: No competing interests were disclosed.

Reviewer Expertise: library and information science, scholarly communication, scholarly publishing 


\section{I confirm that I have read this submission and believe that I have an appropriate level of expertise to confirm that it is of an acceptable scientific standard.}

\section{Version 1}

Reviewer Report 22 May 2017

https://doi.org/10.5256/f1000research.12273.r22576

(C) 2017 Ford E. This is an open access peer review report distributed under the terms of the Creative Commons Attribution License, which permits unrestricted use, distribution, and reproduction in any medium, provided the original work is properly cited.

\section{Emily Ford}

1 Urban \& Public Affairs Librarian, Portland State University, Portland, OR, USA

2 Urban \& Public Affairs Librarian, Portland State University, Portland, OR, USA

Introduction

The definition of open science needs to be clearly stated in the Introduction in order to strengthen the frame of the whole paper. Is the definition you are using of open science fully accepted and not contested? If so, then great, but if not, then it becomes murkier and you might want to spend time unpacking the tension there. Also in the last sentence of the Intro, what is that ethos of open science?

Introduction: Background Would it be useful to unpack some counter arguments on the reasons peer review in its current state of blinded does not work? For example, in the delay and expense portion, how does flipping the model to use APCs change the cost at all? And what happens to unfunded research when the model is flipped? Does that create a disparity that only well funded research is readily available? This might create yet another stratification of scholarly publishing and science communication, which one would assume open science is trying to diminish. I realize that you do some of this in the discussion section, but I find there is a gap in the discussion of the economic argument.

Introduction: Contested Meaning I appreciate your thoughtful criticisms of past works that have been unable to do what you are doing in this article. Being the author of one of them, however, I would like to make some points.

Would like to point out that while I understand the lack of a definition in my authored article (Defining \& Characterizing Open Peer Review - 2013) is problematic, it was never my intent to fully describe it, but I had to use a scope for my systematic review, and that scope was identity disclosure. Please note that in my concluding remarks on that paper that I recommended a definition be more tightly defined, and it never claimed to define it wholesale.

Your research does a good job picking up the task that other papers were unable to accomplish.

Methodology 
I would like to hear more in your methodology section about the searching for and selection of social sciences and humanities literature, as I think there might be some gaps in your data set based on this approach. You provide your search terms for Web of Science, but not the other databases and search engines. Including this would strengthen your

methodology section. To me, the treatment of social sciences and humanities in this study is one of its weaknesses.

Please outline the limitations of your research method.

The methods section should be strengthened for better understanding of social sciences and humanities approaches, as well as limitations, for the paper to be more scientifically sound.

Results

I am not a statistician, nor am I a quantitative researcher, so I cannot provide a robust review of your results when it comes to these facets.

Figures and tables are helpful to translate findings and ideas presented.

Discussion:

This section is well organized and easy to understand. I appreciate the presentation of criticisms of OPR in this section.

Open participation and open interaction sections would be greatly enhanced and do a great service to your consideration of the social sciences and humanities disciplines if you engaged with Fitzpatrick's work presented in the Mellon White paper as well the Logos article. Additionally, there is an article not included in your data set (was it out of scope?), in Social Epistemology, that may help. It would be good to engage more deeply with the question: Is OPR changing the role and purpose of peer review itself? There seems to be evidence of this by the mentorship offered at eLife, the encouragement of reviewers to engage with one another at Frontiers, and generally by collaborative approaches to review that OPR enables. In my view these approaches make peer review more robust, including more than just vetting, fact checking, and some substantive critical feedback. To this end, you will need to more clearly define in your introduction and throughout the paper the assumed purpose of peer review, which you offer us in the open final-versioning commenting portion of the discussion section.

Open platforms section: While I agree that today platforms are an enormous part of our work in communicating science and engaging with our colleagues across the globe. That being said, I would like to point out that the process of peer review could be completely decoupled from a platform. The reason I mention this is that for some individuals and perhaps some disciplines, it might be difficult to get one's head around the distinction between a peer review process and its technological implementation. To me they are distinct, and it is merely digital technology that assists us in allowing OPR to unfold. It behooves shy away from techno determinism when it comes to the possibilities presented by OPR.

Conclusion

I think you have a solid finding, but I would like to point out one more quibble. "Open science" is not a term embraced in the social sciences and humanities. Again, since you are couching your definition under the ethos of open science you will need to better describe open science, and make a bridge for social science and humanities disciplines. If an overarching definition of OPR is to be fully accepted by all disciplines, it needs to be 
inclusive of all of them. This is wherein the tension lies, where the community-based aspect of OPR in the social sciences and humanities (digital humanities?) are much more pronounced in the meaning making of the process. How can you better acknowledge the disciplinary tensions in the paper? Or would you like to scope your findings differently?

Final thoughts

This paper is well written and organized logically, which make it quite readable and easy to follow.

The main weakness of your paper is the lack of nuance addressed between STEM and social sciences and humanities disciplines. Engaging in the the tension between the approaches to and understanding of peer review and OPR in different disciplines will greatly strengthen your paper.

Presenting better the limitations of your method and clarifying your method as noted above will help scope the paper to be more scientifically sound.

Finally, clearly define and scope Open Science so that your proposed definition is more understandable. This will greatly strengthen not only the paper, but the definition itself.

Are the rationale for, and objectives of, the Systematic Review clearly stated?

Yes

Are sufficient details of the methods and analysis provided to allow replication by others? Partly

Is the statistical analysis and its interpretation appropriate?

I cannot comment. A qualified statistician is required.

Are the conclusions drawn adequately supported by the results presented in the review? Partly

Competing Interests: No competing interests were disclosed.

Reviewer Expertise: library and information science, scholarly communication. scholarly publishing

I confirm that I have read this submission and believe that I have an appropriate level of expertise to confirm that it is of an acceptable scientific standard, however I have significant reservations, as outlined above.

Author Response 31 Aug 2017

Tony Ross-Hellauer

Emily Ford: "Introduction: The definition of open science needs to be clearly stated in the Introduction in order to strengthen the frame of the whole paper. Is the definition you are using of open science fully accepted and not contested? If so, then great, but if not, then it becomes murkier and you might want to spend time unpacking the tension there. Also in the last sentence of the Intro, what is that ethos of open science?" 
Tony Ross-Hellauer: I'd like to thank the reviewer for their very thoughtful and helpful comments. The inclusion of more consideration of the SSH perspective, especially, definitely strengthens the paper.

EF: "Introduction: Background - Would it be useful to unpack some counter arguments on the reasons peer review in its current state of blinded does not work? For example, in the delay and expense portion, how does flipping the model to use APCs change the cost at all? And what happens to unfunded research when the model is flipped? Does that create a disparity that only well funded research is readily available? This might create yet another stratification of scholarly publishing and science communication, which one would assume open science is trying to diminish. I realize that you do some of this in the discussion section, but I find there is a gap in the discussion of the economic argument."

TRH: Open Participation relies to an extent on OA (have added a sentence on this), but I'm afraid I don't see a further connection here. Although OPR is of course related to OA journals (in that they have tended to be more likely to experiment with OPR), surely if the same system of (traditional, blinded) peer review is in use, the basic costs (for review) will be the same? I agree that a fully-APC based OA model of publishing has the potential to exclude less well-resourced institutions (especially outside the developed West), but do not follow how this wider argument is connected to OPR. In any case, I believe these considerations fall out of scope of this review (although it would be interesting to follow them up elsewhere).

EF: "Introduction: Contested Meaning - I appreciate your thoughtful criticisms of past works that have been unable to do what you are doing in this article. Being the author of one of them, however, I would like to make some points. - would like to point out that while I understand the lack of a definition in my authored article (Defining \& Characterizing Open Peer Review - 2013) is problematic, it was never my intent to fully describe it, but I had to use a scope for my systematic review, and that scope was identity disclosure. Please note that in my concluding remarks on that paper that I recommended a definition be more tightly defined, and it never claimed to define it wholesale. - Your research does a good job picking up the task that other papers were unable to accomplish."

TRH: Thanks for clarifying this.

EF "Methodology - I would like to hear more in your methodology section about the searching for and selection of social sciences and humanities literature, as I think there might be some gaps in your data set based on this approach. You provide your search terms for Web of Science, but not the other databases and search engines. Including this would strengthen your methodology section. To me, the treatment of social sciences and humanities in this study is one of its weaknesses. Please outline the limitations of your research method. The methods section should be strengthened for better understanding of social sciences and humanities approaches, as well as limitations, for the paper to be more scientifically sound."

TRH: I have expanded the methodology section to better specify search terms and databases used, and included a statement regarding limitations of the search strategy. 
EF: "Results - I am not a statistician, nor am I a quantitative researcher, so I cannot provide a robust review of your results when it comes to these facets. Figures and tables are helpful to translate findings and ideas presented."

TRH: No response required.

EF: "Open participation and open interaction sections would be greatly enhanced and do a great service to your consideration of the social sciences and humanities disciplines if you engaged with Fitzpatrick's work presented in the Mellon White paper as well the Logos article. Additionally, there is an article not included in your data set (was it out of scope?), in Social Epistemology (http://dx.doi.org/10.1080/02691728.2010.498929), that may help. It would be good to engage more deeply with the question: Is OPR changing the role and purpose of peer review itself? There seems to be evidence of this by the mentorship offered at elife, the encouragement of reviewers to engage with one another at Frontiers, and generally by collaborative approaches to review that OPR enables. In my view these approaches make peer review more robust, including more than just vetting, fact checking, and some substantive critical feedback. To this end, you will need to more clearly define in your introduction and throughout the paper the assumed purpose of peer review, which you offer us in the open final-versioning commenting portion of the discussion section."

TRH: I have added consideration of disciplinary differences in the results and discussion sections. In particular, I have added a new figure to show the breakdown of traits by discipline, and added more consideration of the philosophical reasons to consider open participation and interaction. The question of whether OPR is changing the role of peer review per se is an excellent one, but I feel it is out of scope for this paper (which is already long enough!). The article by Fitzpatrick in Social Epistemology was deemed out of scope as it does not mention OPR (save for one mention in a block of quoted text) - the ideas underlying "peer-to-peer review" are no doubt related to the idea of OPR, but the scope here is only those papers which discuss OPR and give an explicit or implicit definition.

EF: "Open platforms section: While I agree that today platforms are an enormous part of our work in communicating science and engaging with our colleagues across the globe. That being said, I would like to point out that the process of peer review could be completely decoupled from a platform. The reason I mention this is that for some individuals and perhaps some disciplines, it might be difficult to get one's head around the distinction between a peer review process and its technological implementation. To me they are distinct, and it is merely digital technology that assists us in allowing OPR to unfold. It behooves shy away from techno determinism when it comes to the possibilities presented by OPR."

TRH: This is an important point - I have added a sentence to the section on final version commenting "In this sense, peer review can be decoupled not only from the journal, but also from any particular platform."

EF: "Conclusion - I think you have a solid finding, but I would like to point out one more quibble. "Open science" is not a term embraced in the social sciences and humanities. Again, since you are couching your definition under the ethos of open science you will need to better describe open science, and make a bridge for social science and humanities disciplines. If an overarching 
definition of OPR is to be fully accepted by all disciplines, it needs to be inclusive of all of them. This is wherein the tension lies, where the community-based aspect of OPR in the social sciences and humanities (digital humanities?) are much more pronounced in the meaning making of the process. How can you better acknowledge the disciplinary tensions in the paper? Or would you like to scope your findings differently?"

TRH: I have added an explicit reference to Open Science, specifically noting that I use the term to include all academic disciplines. I've also added reference to the disciplinary differences found, and included a concluding note that this area needs further research.

EF: "Final thoughts - This paper is well written and organized logically, which make it quite readable and easy to follow. The main weakness of your paper is the lack of nuance addressed between STEM and social sciences and humanities disciplines. Engaging in the the tension between the approaches to and understanding of peer review and OPR in different disciplines will greatly strengthen your paper. Presenting better the limitations of your method and clarifying your method as noted above will help scope the paper to be more scientifically sound. Finally, clearly define and scope Open Science so that your proposed definition is more understandable. This will greatly strengthen not only the paper, but the definition itself."

TRH: Restatement of the above points - see answers above.

Competing Interests: Article author

Reviewer Report 15 May 2017

https://doi.org/10.5256/f1000research.12273.r22575

(C) 2017 Mehmani B. This is an open access peer review report distributed under the terms of the Creative Commons Attribution License, which permits unrestricted use, distribution, and reproduction in any medium, provided the original work is properly cited.

\section{Bahar Mehmani}

${ }^{1}$ Global Publishing Development department, Elsevier, RELX Group, Amsterdam, The Netherlands

2 Global Publishing Development department, Elsevier, RELX Group, Amsterdam, The Netherlands

Tony provides an overview of different definitions of Open Peer Review, acknowledging the ambiguity of the term "open peer review" and the probable impact of such ambiguity on evaluation of the efficiency of open peer review. The author has created then seven OPR traits based on WoS data driven taxonomy. In conclusion though he suggests accepting the existing ambiguity is the only way: "given this is such a contested concept, in my view the only sensible way forward is to acknowledge the ambiguity of this term, accepting that it is used as an umbrella concept for a diverse array of peer review innovations". This doesn't seem to be solving the issue he raises at in beginning. On the contrary considering all peer review innovations as forms of OPR might worsen the current situation. Initiatives like "registered reports", "shortening review deadlines" or "reviewer recognition", which are meant to address result-biased peer review, 
incentivizing reviewers, and boosting review speed, respectively, are certainly peer review innovations but cannot be directly considered as part of the umbrella term of open peer review. Hence the article deserves a stronger conclusion, including perhaps a suggested guideline of clarifying what type of "open peer review" beforehand of any evaluation/discussion using authors seven classifications.

Author can surely strengthen the conclusion by highlighting the lack of evidence in efficiency claims about some of the 7 traits mentioned in the article.

I suggest a double checking the term "Post-publication peer review" in WoS search results. Author reports he has used "Open Final version commenting" for this process in making taxonomy reporting only 6 results. However, Post-publication peer review seem to produce a higher number of documents when I searched the term in Scopus results in 55 documents ( 11 for 2015 and 19 for 2016). This might impact the result reported in Fig. 6 reporting unique configurations of OPR. Although the author reports 22 different definitions there, the figures shows 23 of them.

It is also worth mentioning most of OPR initiatives mentioned in the article are not directly addressing all of shortcomings of the current peer review process. Mainly because one should distinguish between editorial process and peer review process. Issues such as delay and expense are universal to single/double/open peer review as they are part of the editorial process.

Are the rationale for, and objectives of, the Systematic Review clearly stated?

Yes

Are sufficient details of the methods and analysis provided to allow replication by others? Yes

Is the statistical analysis and its interpretation appropriate?

Yes

Are the conclusions drawn adequately supported by the results presented in the review? Partly

Competing Interests: No competing interests were disclosed.

Reviewer Expertise: Peer review innovations

I confirm that I have read this submission and believe that I have an appropriate level of expertise to confirm that it is of an acceptable scientific standard, however I have significant reservations, as outlined above.

Author Response 31 Aug 2017

Tony Ross-Hellauer

Bahar Mehmani: "Tony provides an overview of different definitions of Open Peer Review, acknowledging the ambiguity of the term "open peer review" and the probable impact of such 
ambiguity on evaluation of the efficiency of open peer review. The author has created then seven OPR traits based on WoS data driven taxonomy. In conclusion though he suggests accepting the existing ambiguity is the only way: "given this is such a contested concept, in my view the only sensible way forward is to acknowledge the ambiguity of this term, accepting that it is used as an umbrella concept for a diverse array of peer review innovations". This doesn't seem to be solving the issue he raises at in beginning. On the contrary considering all peer review innovations as forms of OPR might worsen the current situation. Initiatives like "registered reports", "shortening review deadlines" or "reviewer recognition", which are meant to address result-biased peer review, incentivizing reviewers, and boosting review speed, respectively, are certainly peer review innovations but cannot be directly considered as part of the umbrella term of open peer review. Hence the article deserves a stronger conclusion, including perhaps a suggested guideline of clarifying what type of "open peer review" beforehand of any evaluation/discussion using authors seven classifications."

Tony Ross-Hellauer: I thank the reviewer for their time and care in preparing this helpful review report, which has helped to improve the second version. I understand the concern about merely accepting ambiguity to be no way to overcome confusion. I share this view and have now added/altered text to make my intentions clearer - "Given that OPR is such a contested concept, in my view the only sensible way forward is to acknowledge the ambiguity of this term, accepting that it is used as an umbrella concept for a diverse array of peer review innovations. Although it could be argued that merely accepting the status quo in this way does not help resolve possible confusion regarding usage, I would argue that quantifying the ambiguity of usage and mapping the distinct traits enables future discussion to start from a firmer basis that (1) acknowledges that people often mean different things when they use this term, and (2) clarifies in advance exactly which OPR traits are under discussion."

BM: "Author can surely strengthen the conclusion by highlighting the lack of evidence in efficiency claims about some of the 7 traits mentioned in the article."

TRH: I have included this point in the expanded conclusion.

BM: "I suggest a double checking the term "Post-publication peer review" in WoS search results. Author reports he has used "Open Final version commenting" for this process in making taxonomy reporting only 6 results. However, Post-publication peer review seem to produce a higher number of documents when I searched the term in Scopus results in 55 documents 11 for 2015 and 19 for 2016). This might impact the result reported in Fig. 6 reporting unique configurations of OPR."

TRH: Although there is obvious overlap between the terms "open peer review" and "postpublication peer review", and so the literature on PPPR is useful to understand these phenomena, this study is only an attempt to categorize uses of the former term - hence, articles on PPPR which did not mention OPR were out of scope.

BM: "Although the author reports 22 different definitions there, the figures shows 23 of them."

TRH: The original figure was wrong and has been corrected. The final row of the original 
figure was a duplicate of the 12 th entry ( $n=1$, open reports, participation, manuscripts). I thank the reviewer very much for their attention to detail in spotting this silly error! Hence, it is correct that there are 22 different definitions.

BM: "It is also worth mentioning most of OPR initiatives mentioned in the article are not directly addressing all of shortcomings of the current peer review process. Mainly because one should distinguish between editorial process and peer review process. Issues such as delay and expense are universal to single/double/open peer review as they are part of the editorial process."

TRH: I address this point with added text in the background and conclusion sections.

Competing Interests: Article author

Reviewer Report 11 May 2017

https://doi.org/10.5256/f1000research.12273.r22301

(C) 2017 Bloom T. This is an open access peer review report distributed under the terms of the Creative Commons Attribution License, which permits unrestricted use, distribution, and reproduction in any medium, provided the original work is properly cited.

\section{Theodora Bloom}

1 The BMJ, London, UK

2 The BMJ, London, UK

This is an interesting paper addressing a question that is important to journal editors and publishers as well as the wider 'open science' community, namely what is meant by open peer review. I have three significant concerns that need to be addressed, followed by more minor annotations and comments.

Major issues, in the order they arise in the article

1. Would this meet most established criteria for a systematic review? Although the author completes a PRISMA checklist, he also notes firstly that he searched Web of Science, then that he added a bunch of other sources, and finally, "This set of articles was further enriched with 42 definitions from sources found through searching for the same terms in other academic databases (e.g., Google Scholar, JSTOR, disciplinary databases), Google (for blog articles) and Google Books (for books), as well as following citations in relevant bibliographies and literature reviews." This suggests that it is not really systematic (although the author is to be applauded for providing the data he worked from). There is a lack of clarity about the universe of literature that is being assessed, and of details about how it was assessed. In my view, the article is still a worthwhile undertaking, despite being non-systematic, but the title ought to reflect this. 
2. In my view the author does not pay enough attention to one important variant of open review, namely real-time review in the open, in which either invited reviewers or 'the crowd' comment on an article, with comments being posted as they are ready, rather than at the end of a formal process of peer review and decision-making. Conversely, the inclusion of 'open platforms' seems very confusing to me, as they do not have many of the criteria of openness that define the other flavours of open review that the author describes, but instead are about decoupling peer review from publication. Indeed Figure 6 makes plain that as a trait open platforms only occur twice in the 122 definitions considered. I would bet that the 'real-time' variant occurs far more often, and ought to be included as one of the key traits within the umbrella definition.

3. In a paper that aims to define open peer review, it is unfortunate that the author doesn't spend longer considering alternative definitions of peer review. Throughout the article he appears to conflate editorial selection (whether a journal accepts a manuscript) with technical review (whether the work is sound and properly reported). Thus when he talks about the "problems with peer review" he is sometimes talking about reviewers not spotting technical problems, sometimes about editors rejecting articles that don't suit their taste, and sometimes about authors going through cycles of editorial rejection to achieve a high impact publication. Conflating these various things does not provide a sound foundation on which to build a definition of open peer review. This conflation is made worse when, for example, it is implied that the only reason for retraction is error. Thus most of the first three paragraphs of the 'background' section, and much of what follows about biases, incentives and wastefulness are muddled, and the references and evidence do not all support the broad claims made about 'peer review' (itself an 'umbrella term').

More minor concerns, with page numbers (PDF version) of the corresponding text Abstract and later: The author needs to decide throughout the article whether he is singular (as he appears to be) or uses the royal 'we'.

p7 - it is not helpful to list the seven types of openness without definitions. Even if the lengthy discussion of them follows later, I was desperate for some brief definition, in particular for the last two, and was labouring under a misapprehension about the meaning of the fourth, until much later in the article when I discovered what was meant by 'open prereview manuscripts'.

p8 - proponents of open identity review in medicine would also point out that it makes conflicts of interest much more apparent and subject to scrutiny.

p8 - some journals use open reports without open identities - i.e. posting reports with published articles but without identifying the reviewer (e.g. http://embor.embopress.org/about\#Transparent_Process). The author writes as if open reports must always have open identities.

p10 - I think 'open pre-review manuscripts' is the wrong name for what the author is describing. At first I thought this meant the practice of posting the authors' version of a manuscript alongside the peer review history (as is done by The BMJ, for example). But I think the author means 'Open posting before formal review' (which some call preprints). He 
might like to consider the suggestions by Neylon et al. about this issue of terminology (http://biorxiv.org/content/early/2016/12/09/092817)

p10 - I wonder if the author has any evidence that PubPeer has been 'a major influence'?

p11 - I don't think 'open platforms' is the right term either. (Although as noted above, I don't really think this section belongs in the discussion at all, if it is to remain I would strongly recommend renaming it.) In publishing terms a platform is 'where' you publish articles, and the author is here discussing an aspect of how you get to the point of publication, and in particular peer review services (which as far as I can tell de facto meet only rather limited criteria of openness). I think what the author is describing is peer review options decoupled from journals (see Priem and Hemminger, Front Comput Neurosci 2012; 6: 19) and as noted I don't understand why these have a place in a definition of open peer review.

p11 - Conclusion. I don't believe the author presents a unified definition of open peer review, for all the reasons discussed above, but he does present most of the traits that together come under the umbrella term.

Are the rationale for, and objectives of, the Systematic Review clearly stated? Yes

Are sufficient details of the methods and analysis provided to allow replication by others? Partly

Is the statistical analysis and its interpretation appropriate? Not applicable

Are the conclusions drawn adequately supported by the results presented in the review? Partly

Competing Interests: I am Executive Editor of The BMJ, which operates a version of open peer review, and I have previously been employed by PLOS and BioMed Central which operate different versions.

Reviewer Expertise: I am a journal editor. I have operated a couple of different variants of open peer review.

I confirm that I have read this submission and believe that I have an appropriate level of expertise to confirm that it is of an acceptable scientific standard, however I have significant reservations, as outlined above.

Author Response 31 Aug 2017

Tony Ross-Hellauer

Theodora Bloom: "This is an interesting paper addressing a question that is important to journal 
editors and publishers as well as the wider 'open science' community, namely what is meant by open peer review. I have three significant concerns that need to be addressed, followed by more minor annotations and comments."

Tony Ross-Hellauer: I'd like to thank the reviewer for their time and care in undertaking this review, which has helped strengthen the paper, especially with regards to the suggestions for strengthening the analysis of the problems with peer review.

TB: Would this meet most established criteria for a systematic review? Although the author completes a PRISMA checklist, he also notes firstly that he searched Web of Science, then that he added a bunch of other sources, and finally, "This set of articles was further enriched with 42 definitions from sources found through searching for the same terms in other academic databases (e.g., Google Scholar, JSTOR, disciplinary databases), Google (for blog articles) and Google Books (for books), as well as following citations in relevant bibliographies and literature reviews." This suggests that it is not really systematic (although the author is to be applauded for providing the data he worked from). There is a lack of clarity about the universe of literature that is being assessed, and of details about how it was assessed. In my view, the article is still a worthwhile undertaking, despite being non-systematic, but the title ought to reflect this.

TRH: I have strengthened the description in the methods section to address this criticism. I do believe this article meets the criteria for PRISMA systematic reviews (the relevant sections from the PRISMA checklist being: "7. - Describe all information sources (e.g., databases with dates of coverage, contact with study authors to identify additional studies) in the search and date last searched"; and "8. Present full electronic search strategy for at least one database, including any limits used, such that it could be repeated." )

TB: "In my view the author does not pay enough attention to one important variant of open review, namely real-time review in the open, in which either invited reviewers or 'the crowd' comment on an article, with comments being posted as they are ready, rather than at the end of a formal process of peer review and decision-making. Conversely, the inclusion of 'open platforms' seems very confusing to me, as they do not have many of the criteria of openness that define the other flavours of open review that the author describes, but instead are about decoupling peer review from publication. Indeed Figure 6 makes plain that as a trait open platforms only occur twice in the 122 definitions considered. I would bet that the 'real-time' variant occurs far more often, and ought to be included as one of the key traits within the umbrella definition."

TRH: I thank the reviewer for pointing out the gap in not mentioning what they term "realtime review in the open" - but I would respectfully disagree with the reviewer that this feature constitutes a core trait. In my view it depends upon other traits, including open reports, commenting, participation and especially open pre-review manuscripts. As this feature depends (in my view) most fully upon open pre-review manuscripts (since the manuscript would need to be online to begin the process), I have included mention of this option in the discussion section for that trait with the added text: "Finally, making manuscripts openly available in advance of review allows comments to be posted as they are received, either from invited reviewers or the wider community, and enabling readers to follow the process of peer-review in real-time." 
TB: "In a paper that aims to define open peer review, it is unfortunate that the author doesn't spend longer considering alternative definitions of peer review. Throughout the article he appears to conflate editorial selection (whether a journal accepts a manuscript) with technical review (whether the work is sound and properly reported). Thus when he talks about the "problems with peer review" he is sometimes talking about reviewers not spotting technical problems, sometimes about editors rejecting articles that don't suit their taste, and sometimes about authors going through cycles of editorial rejection to achieve a high impact publication. Conflating these various things does not provide a sound foundation on which to build a definition of open peer review. This conflation is made worse when, for example, it is implied that the only reason for retraction is error. Thus most of the first three paragraphs of the 'background' section, and much of what follows about biases, incentives and wastefulness are muddled, and the references and evidence do not all support the broad claims made about 'peer review' (itself an 'umbrella term')."

TRH: Since the aim of this article was to clarify, I am very grateful to the reviewer for pointing out the ways in which this section actually confuses things. It was certainly not my intention to insinuate that OPR is a panacea for all problems with traditional peer review. I have added text to address the reviewer's comments: (a) The description of traditional peer review in the Background section has been revised to clarify the role of peer review in scholarly communication; (b) Two new sections have been added to the discussion which make clearer (1) the particular problems with traditional peer review that each OPR trait aims to address, and (2) how each trait can be related to the broader agenda of Open Science (a new figure is also added).

TB: "Abstract and later: The author needs to decide throughout the article whether he is singular (as he appears to be) or uses the royal 'we'."

\section{TRH: Corrected}

TB: "p7 - it is not helpful to list the seven types of openness without definitions. Even if the lengthy discussion of them follows later, I was desperate for some brief definition, in particular for the last two, and was labouring under a misapprehension about the meaning of the fourth, until much later in the article when I discovered what was meant by 'open pre-review manuscripts.' "

TRH: Definitions added.

TB: "p8 - proponents of open identity review in medicine would also point out that it makes conflicts of interest much more apparent and subject to scrutiny."

TRH: Added text to address this: "Finally, a reviewer for this paper advises that "proponents of open identity review in medicine would also point out that it makes conflicts of interest much more apparent and subject to scrutiny" (Bloom, 2017). "

TB: " $p 8$ - some journals use open reports without open identities - i.e. posting reports with published articles but without identifying the reviewer (e.g.

http://embor.embopress.org/about\#Transparent_Process). The author writes as if open reports 
must always have open identities."

TRH: Added sentence to clarify: "Often, although not in all cases (e.g., EMBO reports, http://embor.embopress.org), review names are published alongside the reports. "

TB: "p10 - I think 'open pre-review manuscripts' is the wrong name for what the author is describing. At first I thought this meant the practice of posting the authors'version of a manuscript alongside the peer review history (as is done by The BMJ, for example). But I think the author means 'Open posting before formal review' (which some call preprints). He might like to consider the suggestions by Neylon et al. about this issue of terminology (http://biorxiv.org/content/early/2016/12/09/092817)"

TRH: I agree the terminology could be misconstrued, but am not sure the reviewer's suggestion is preferable (the phrase "posting" could be thought ambiguous) - to avoid ambiguity for future readers, I have added definitions on p7 where I introduce the terms.

TB: "p10 - I wonder if the author has any evidence that PubPeer has been 'a major influence'?"

TRH: I've weakened the terminology to "An important platform in this regard has been major influence here has been the independent platform Pubpeer "

TB: "p11 - I don't think 'open platforms' is the right term either. (Although as noted above, I don't really think this section belongs in the discussion at all, if it is to remain I would strongly recommend renaming it.) In publishing terms a platform is 'where' you publish articles, and the author is here discussing an aspect of how you get to the point of publication, and in particular peer review services (which as far as I can tell de facto meet only rather limited criteria of openness). I think what the author is describing is peer review options decoupled from journals (see Priem and Hemminger, Front Comput Neurosci 2012; 6: 19) and as noted I don't understand why these have a place in a definition of open peer review."

TRH: I respectfully disagree with the reviewer here - the word "platform" seems to be used more broadly - e.g., PubPeer considers itself an "online platform for post-publication peer review" - however, I agree that the terminology might be confusing and so have changed the wording to "Open platforms ("decoupled review")". The point about open platforms being a fringe trait is valid (I've added text to the open platforms section in the discussion to strengthen the acknowledgement of this) - it was included simply because it was observed to be part of the two definitions cited.

TB: "p11 - Conclusion. I don't believe the author presents a unified definition of open peer review, for all the reasons discussed above, but he does present most of the traits that together come under the umbrella term."

TRH: I have removed the term "unified" as this is no doubt contentious

Competing Interests: Article author 
Reviewer Report 08 May 2017

https://doi.org/10.5256/f1000research.12273.r22299

(C) 2017 Walker R. This is an open access peer review report distributed under the terms of the Creative Commons Attribution License, which permits unrestricted use, distribution, and reproduction in any medium, provided the original work is properly cited.

\section{Richard Walker}

1 Blue Brain Project, Swiss Federal Institute of Technology in Lausanne, Geneva, Switzerland

2 Blue Brain Project, Swiss Federal Institute of Technology in Lausanne, Geneva, Switzerland

\section{General}

This is a useful, well-written article that helps to clarify some of the "fuzziness" concerning the concept of "Open Peer Review".

The author makes a systematic search of the literature, fully and correctly detailing his methods in the Supplementary Materials. His main conclusion is that "Open peer review is an umbrella term for a number of overlapping ways that peer review models can be adapted in line with the ethos of Open Science...". The data from the systematic review fully justifies this conclusion. The references are comprehensive and up to date.

On this basis, I believe the quality of the article is already sufficient to justify publication. I would like, nonetheless to suggest some possibilities for improvement.

\section{Weak conclusions}

The author's conclusions, while correct, are weak. The rapid growth in references to Open Peer Review in the literature suggests that interest in OPR is growing rapidly. It would be useful to point this out. It would also be useful to point out that 110/122 references in his survey talk about "Open Identities" and 72 talk about Open Reports". This suggests to me that the core sense of Open Peer Review lies precisely in the use of Open identifies and Open Reports and that other aspects are more peripheral. If this were my article (which it is not) I would make this core/periphery distinction more explicit. The author observes correctly that there is still very little evidence about the effectiveness or otherwise of different forms of Open Peer Review. This is another issue that it would be good to bring out in the conclusions.

\section{"Power distribution" -}

The author claims that the configurations of OPR traits "follow a power-law distribution". Readers will understand what he means. However a power law is a functional relationship between two quantities - and here I see only one (the number of configurations). Power laws play no further part in the author's argument. So I suggest it would be better to avoid the term. What the author could say, correctly, is that there are a couple of very common configurations and a lot of rarer ones. This links to the idea of a "core" and "peripheral" concepts of OPR. 


\section{Reasons for open reports}

The author correctly argues that Open Identities provide an incentive to reviewers to do their work thoroughly. I suggest that the same applies to "Open Reports". No reviewer wants to expose himself/herself as lazy or blatantly unfair.

\section{Detailed points.}

P4: I suggest the author replaces "Unaccountability" with "Lack of accountability" P6: In the methods, there seem to be two literature surveys, the first by OpenAire (never mentioned again in the rest of the article), the second by the author. The author should clarify exactly who did what and how he used the OpenAire search

P6: The text at the top of column 2 starts in the middle of a sentence. I think something is missing.

P7: In Figure 4, it is not clear what is the metric. Is it the number of Journal Articles/Grant proposals etc. or is it the number of distinct definitions found in journals etc? It would be good to clarify what is meant by "Data,Journal Articles"

- P7: The author writes that "for the literature offers a total of 22 distinct configurations of seven traits, effectively meaning that there are 22 different definitions of OPR in the literature." In reality he found 22 configurations in his, necessarily limited survey. I am certain the literature contains many more. I suggest he corrects his initial statement to make this clear.

P7: The definition of "Open identities", "Open Reports" etc. is given in the discussion. I suggest it would be useful to insert the definitions, earlier, immediately after the introduction of the schema (column $2 \mathrm{p} 7$ )

P8: It might be worth mentioning that some publishers (like Frontiers) favor a system of Open Peer Review which publishes reviewers' names, only when articles are accepted, thereby avoiding the risk of self-censorship by critical reviewers.

Are the rationale for, and objectives of, the Systematic Review clearly stated? Yes

Are sufficient details of the methods and analysis provided to allow replication by others? Yes

Is the statistical analysis and its interpretation appropriate?

Not applicable

Are the conclusions drawn adequately supported by the results presented in the review? Yes

Competing Interests: I am a consultant for Frontiers Media SA, an Open Access publisher with its own system of Open Peer Review

I confirm that I have read this submission and believe that I have an appropriate level of 


\section{expertise to confirm that it is of an acceptable scientific standard.}

Author Response 31 Aug 2017

\section{Tony Ross-Hellauer}

Richard Walker: "This is a useful, well-written article that helps to clarify some of the "fuzziness" concerning the concept of "Open Peer Review". The author makes a systematic search of the literature, fully and correctly detailing his methods in the Supplementary Materials. His main conclusion is that "Open peer review is an umbrella term for a number of overlapping ways that peer review models can be adapted in line with the ethos of Open Science...". The data from the systematic review fully justifies this conclusion. The references are comprehensive and up to date. On this basis, I believe the quality of the article is already sufficient to justify publication. I would like, nonetheless to suggest some possibilities for improvement."

Tony Ross-Hellauer: I'd like to personally thank the reviewer for their time and care in undertaking this review, which has helped strengthen the paper, especially with regards to the suggestions for strengthening the conclusion.

RW: Weak conclusions - The author's conclusions, while correct, are weak. The rapid growth in references to Open Peer Review in the literature suggests that interest in OPR is growing rapidly. It would be useful to point this out. It would also be useful to point out that 110/122 references in his survey talk about "Open Identities" and 72 talk about Open Reports". This suggests to me that the core sense of Open Peer Review lies precisely in the use of Open identifies and Open Reports and that other aspects are more peripheral. If this were my article (which it is not) I would make this core/periphery distinction more explicit. The author observes correctly that there is still very little evidence about the effectiveness or otherwise of different forms of Open Peer Review. This is another issue that it would be good to bring out in the conclusions.

TRH: I agree that the conclusion was weak and welcome the suggestions for improvement. I have written an extended conclusion which I believe addresses all these points.

RW: "'Power distribution" - The author claims that the configurations of OPR traits "follow a power-law distribution". Readers will understand what he means. However a power law is a functional relationship between two quantities - and here I see only one (the number of configurations). Power laws play no further part in the author's argument. So I suggest it would be better to avoid the term. What the author could say, correctly, is that there are a couple of very common configurations and a lot of rarer ones. This links to the idea of a "core" and "peripheral" concepts of OPR."

TRH: Text changed to "The distribution of traits shows two very popular configurations and a variety of rarer ones..."

RW: "Reasons for open reports - The author correctly argues that Open Identities provide an incentive to reviewers to do their work thoroughly. I suggest that the same applies to "Open Reports". No reviewer wants to expose himself/herself as lazy or blatantly unfair."

TRH: Agreed - I have added text to this effect: "It could also increase review quality, as the 
thought of their words being made publicly available could motivate reviewers to be more thorough in their review activities. "

\section{RW: "P4: I suggest the author replaces "Unaccountability" with "Lack of accountability"'"}

TRH: Text changed as suggested.

RW: "P6: In the methods, there seem to be two literature surveys, the first by OpenAire (never mentioned again in the rest of the article), the second by the author. The author should clarify exactly who did what and how he used the OpenAire search"

TRH: There was only one lit review, done by the main author as part of the OpenAIRE project - for clarity, I've changed the reference to OpenAIRE to the first person singular ("I")

RW: "P6: The text at the top of column 2 starts in the middle of a sentence. I think something is missing."

TRH: I've changed the structure of this sentence to be less confusing: "Sixty-eight percent $(n=83)$ of the 122 definitions identified were explicitly stated, $37.7 \%(n=46)$ implicitly stated, and $5.7 \%(n=7)$ contained both explicit and implicit information."

RW: "P7: In Figure 4, it is not clear what is the metric. Is it the number of Journal Articles/Grant proposals etc. or is it the number of distinct definitions found in journals etc? It would be good to clarify what is meant by "Data,Journal Articles"'"

TRH: This is explained in the text at the bottom of $\mathrm{p} 5$ of $\mathrm{v} 1$ : "Meanwhile, regarding the target of the OPR mentioned in these articles (Figure 4), most were referring to peer review of journal articles $(80.7 \%)$, with $16 \%$ not specifying a target $(16 \%)$, and a small number of articles also referring to review of data, conference papers and grant proposals."

RW: "P7: The author writes that "for the literature offers a total of 22 distinct configurations of seven traits, effectively meaning that there are 22 different definitions of OPR in the literature." In reality he found 22 configurations in his, necessarily limited survey. I am certain the literature contains many more. I suggest he corrects his initial statement to make this clear."

TRH: Added text to sentence to read "in the literature examined here."

RW: "P7: The definition of "Open identities", "Open Reports" etc. is given in the discussion. I suggest it would be useful to insert the definitions, earlier, immediately after the introduction of the schema (column $2 p$ 7)"

TRH: Text added as suggested.

RW: "P8: It might be worth mentioning that some publishers (like Frontiers) favor a system of Open Peer Review which publishes reviewers' names, only when articles are accepted, thereby avoiding the risk of self-censorship by critical reviewers."

TRH: This is a good suggestion. 
Competing Interests: Article author

\section{Comments on this article}

\section{Version 2}

Reader Comment ( ) 07 Sep 2017

Mick Watson

My comments on this are well summarized in the opinion piece I published in Genome Biology some time ago: https://genomebiology.biomedcentral.com/articles/10.1186/s13059-015-0669-2

Competing Interests: No competing interests were disclosed.

The benefits of publishing with F1000Research:

- Your article is published within days, with no editorial bias

- You can publish traditional articles, null/negative results, case reports, data notes and more

- The peer review process is transparent and collaborative

- Your article is indexed in PubMed after passing peer review

- Dedicated customer support at every stage

For pre-submission enquiries, contact research@f1000.com 